\title{
Finite Element Model of a Filament-Wound Composite Tube Subjected to Uniaxial Tension
}

\author{
Gyula Szabó, Károly Váradi, Dávid Felhős \\ Department of Machine and Product Design, Budapest University of Technology and Economics, Budapest, Hungary \\ Email: szabo.gyula@gt3.bme.hu
}

How to cite this paper: Szabó, G., Váradi, K. and Felhős, D. (2017) Finite Element Model of a Filament-Wound Composite Tube Subjected to Uniaxial Tension. Modern Mechanical Engineering, 7, 91-112. https://doi.org/10.4236/mme.2017.74007

Received: August 2, 2017

Accepted: October 10, 2017

Published: October 13, 2017

Copyright $\odot 2017$ by authors and Scientific Research Publishing Inc. This work is licensed under the Creative Commons Attribution International License (CC BY 4.0).

http://creativecommons.org/licenses/by/4.0/

\begin{abstract}
The aim of this paper is to demonstrate the mechanical behaviour of a filament-wound composite tube subjected to uniaxial tension by finite element analysis. Uniaxial tensile test experiments have been carried out on standard specimen and hose piece in order to verify finite element models and material properties and also to assess failure mode of composite plies. Composite reinforcement plies are modeled as linear orthotropic, while elastomer liners are described by hyperelastic material model. Results of finite element models and experiments show good agreement in the initial phase of uniaxial tension, which justifies utilized material models in the operating range. Results of finite element models show that transverse tension and shear load are dominant under tension. It is determined that principal failure mode of reinforcement plies is intra-ply yarn-matrix debonding caused by intensive shear of rubber matrix.
\end{abstract}

\section{Keywords}

Filament-Wound Composite Tube, Uniaxial Tension, Tensile Test, Debonding, Damage, Finite Element Analysis

\section{Introduction}

Composite tubes find extensive use in numerous different industrial fields; in transportation, oil industry, aerospace and aeronautical applications [1]. The most advantageous properties of polymeric-based tubes are high stiffness-to-weight ratio and corrosion resistance. Among manufacturing processes of composite tubes, filament winding is prominent because of high precision fibre positioning, high fibre content, low void content and good automation capability [2]. The most common operational loads are: internal pressure, axial and 
biaxial tension and buckling due to bending [3]. For balancing the internal forces, angles of $\pm \Theta$ are generally adopted [4]. Optimal winding angles depend on the expected loading cases [5]. When solely internal pressure is applied the optimal winding angle is $\pm 75^{\circ}$, when loading is purely uniaxial winding angle needs to be as low as possible-taking into account manufacturing considerations, in case of combined internal pressure and axial loading-where ratio of circumferential to axial stress is $2: 1, \pm 55^{\circ}$ is adopted [6], [7]. The lattermost is the most commonly encountered [8]. Rubber matrix gives the composite material favourable deformability, high flexibility and toughness.

One efficient method of obtaining material properties of a composite part is conducting uniaxial tensile test on a standard test specimen cut from a hose (in accordance with standard ASTM D638) or on a hose piece itself. Material properties in the operating range are to be determined from the initial section of the force-displacement curve characterized by constant slope. The following nonlinear section holds significance for investigating the failure procedure. [9].

Bai et al. [10] manifested that in the initial phase of the uniaxial tension of a tensile specimen, microcracks appeared in the zone free of fibres, classified as mode I microcracks perpendicular to the loading direction. Microcracks are principally originated from porosity which can be either intra-ply or inter-ply in nature (intra-ply porosity is located inside the plies, inter-ply porosity is located in the interface layer between plies). Then, increasing tension brought about transverse cracking, which resulted in the debonding of fibre and matrix within plies.

Mechanical characterization of composite tubes is most frequently carried out by finite element models. [11]

The most widely used means of determining material properties of composite parts is usage of formulae of rules of mixture, which give estimation on elastic constants based on material properties of the reinforcing yarn and the matrix. In finite element models, plies are represented as laminates whose material properties are usually calculated with the use of the rules of mixtures. [12]

In this paper, material properties of a composite tube are elaborated with the above-mentioned approach (Chapter 2) followed by the tensile test experiment (Chapter 3) and the finite element simulation (Chapter 4) of the standard test specimen cut from the tube. Furthermore, tensile test experiment (Chapter 5) and finite element simulation (Chapter 6) of a hose piece are presented. Afterwards, comparison of results and conclusions end this article.

These analyses serve as a basis for verification of composite material properties and isotropic material properties as well, moreover, failure procedure of standard test specimen has been investigated. Stress states and strain states of finite element models corroborate assumed failure mode of composite plies. Experimental data and simulation results of standard test specimen and hose piece have been compared to one another, by which differences in mechanical behaviour of standard test specimen and hose piece have been demonstrated. 


\section{Material Properties of Reinforcement Plies}

Determination of material properties of reinforcement plies has been accomplished by the method illustrated in Figure 1. Firstly, photographs have been taken at the cross-section of the hose, in which yarns are respresented by their angular sections (end section). By using KLONK image measurement software [13], average area of yarns has been calculated in their end sections. Average area of yarns in the end section has been utilized for the determination of fibre volume fraction. Then, average cross-sectional area of yarns has been calculated with the help of the orientation angle and average area of yarns in the end section. Afterwards, modulus of elasticity of fibre has been evaluated based on the load-strain curves of a reinforcement yarn and the average cross-sectional area of a reinforcement yarn. Two parameter Mooney-Rivlin material model has been fitted to stress-strain curves of rubber liners, therefore modulus of elasticity of matrix, being made of rubber, has been calculated. Finally, composite elastic constants have been derived based on modulus of elasticity of fibre, modulus of elasticity of matrix and fibre volume fraction.

Material properties of reinforcement plies can be determined in view of their geometric parameters and the tensile properties of the fibre and the matrix. As regards the geometric parameters, average area of yarns and fibre volume fraction are fundamental.

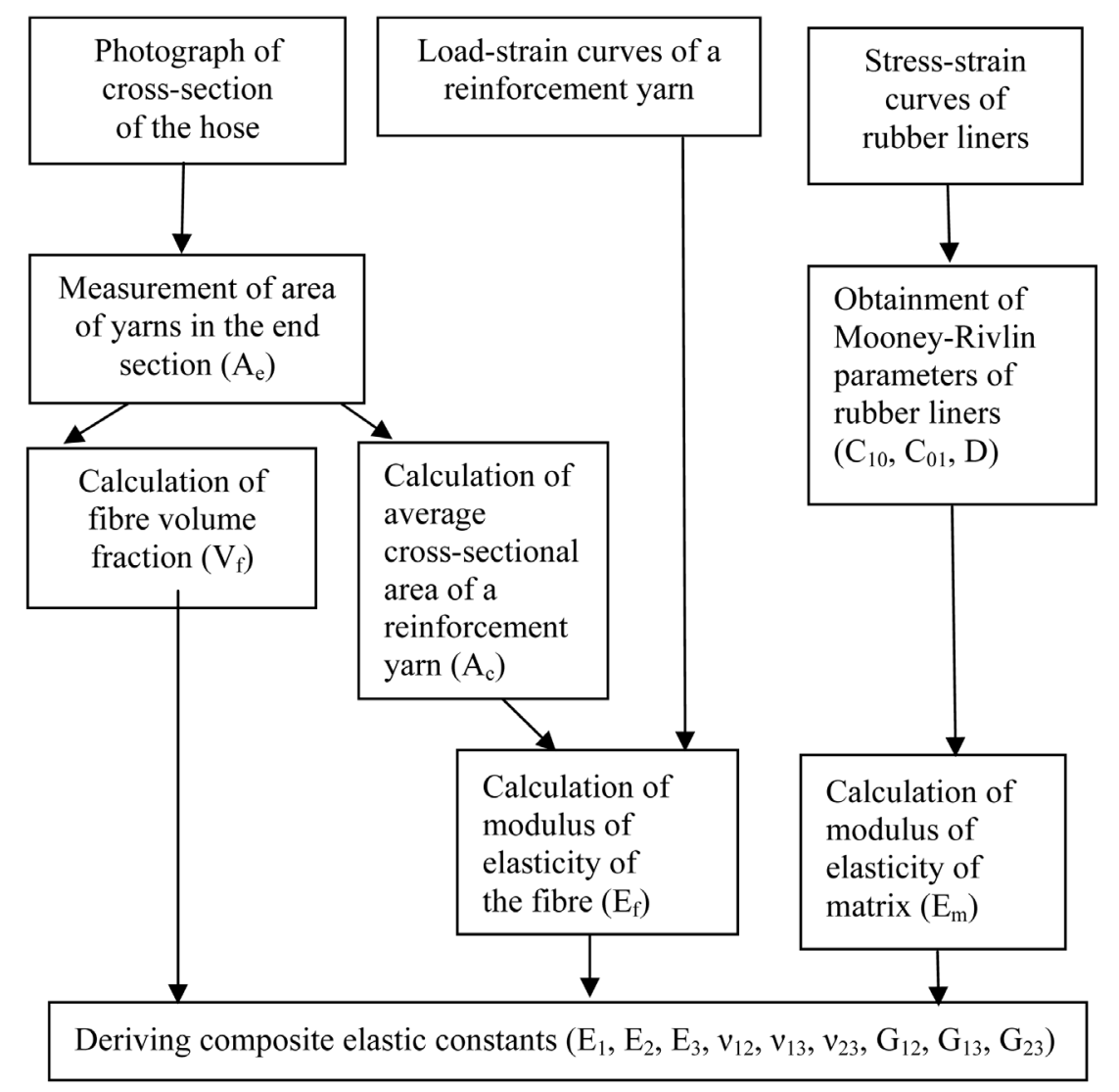

Figure 1. Flow diagram of determination of material properties of reinforcement plies. 
Computation of area has been carried out by KLONK image measurement software [13].

In Figure 2, captured perpendicular to the axis of the hose (end section of yarns), yarns are surrounded by measurement splines. Average area of the yarns determined with the help of the software is $0.61 \mathrm{~mm}^{2}$. Outlines of the yarns might be regarded as ellipses with good approximation.

In Figure 2, yarns are represented by their angular cut surfaces because the included angle of the yarns and the axis of the hose is $\omega=55^{\circ}$. This angular cut is not representative when estimating elastic constants; therefore the cross-sectional area needs to be evaluated in this case (Figure 3). In the angular section of the yarn, the included angle of the ellipse and the normal to the cross-sectional plane is $\omega$, hence

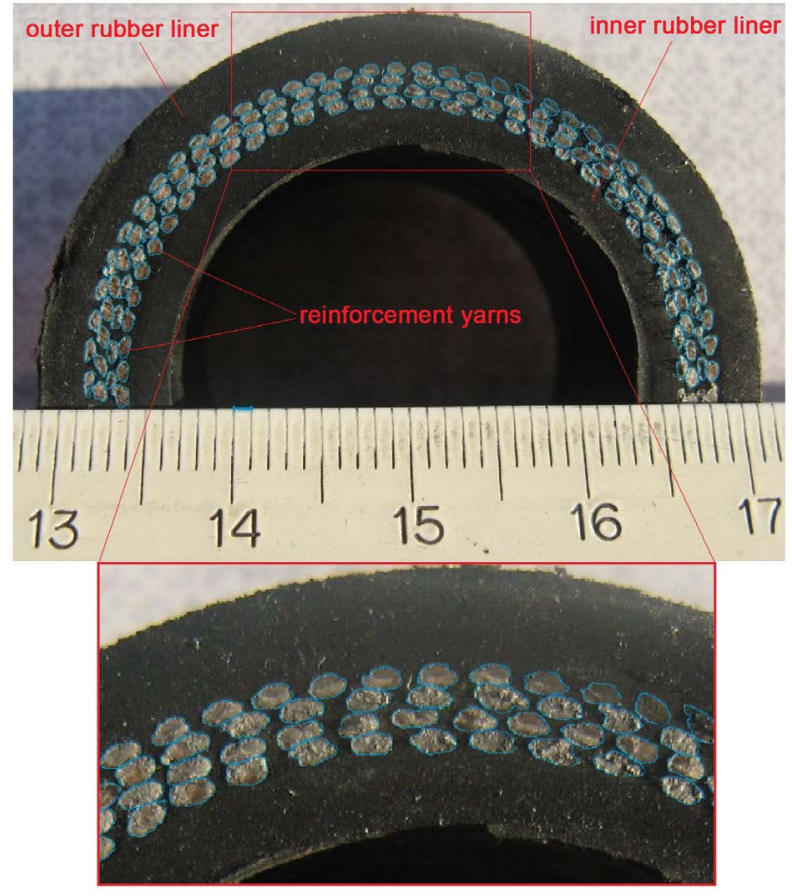

Figure 2. Cross-section of the hose with measured yarns, a segment enlarged and the calibration length ( $1 \mathrm{~mm}$ between $14 \mathrm{~cm}$ and $14.1 \mathrm{~cm}$ of the ruler).
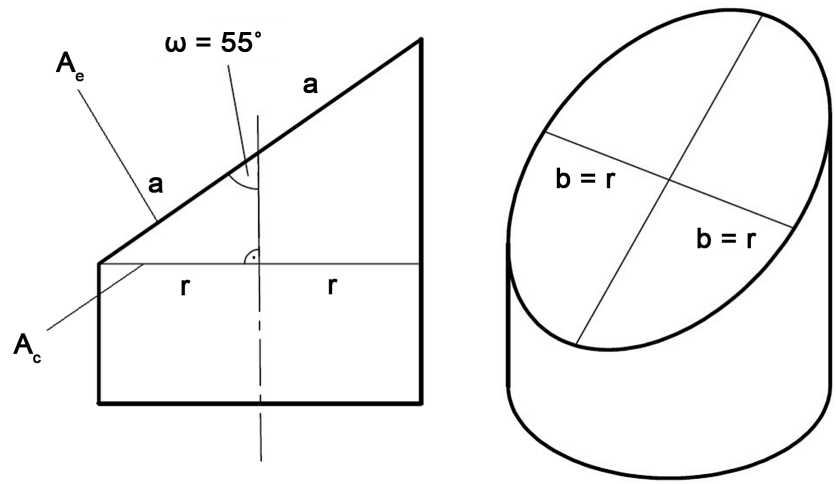

Figure 3. Angular section (end section) of a yarn at the cross-section of the hose. 


$$
r=a \cdot \sin \omega \text { while } r=b
$$

where $r$ stands for the radius of the circular cross-section

$a$ is the semi-major axis of the elliptical end section

$b$ is the semi-minor axis of the elliptical end section

$\omega$ is the orientation angle

Therefore, area of the yarn in its cross-section equals:

$$
A_{c}=A_{e} \cdot \sin \omega
$$

where $A_{c}$ stands for the area of cross-section of yarn-perpendicular to its axis $A_{e}$ stands for the area of the angular end section of yarn-taken at the cross section of the hose.

Figure 4 shows orientation of the reinforcement plies related to the axis of the hose. The orientation angle is congruent with the included angle of the angular section of the yarn (end section) and the normal to the cross-sectional plane of the yarn.

\subsection{Fibre Volume Fraction}

Volume fraction has been calculated as the proportion of the end sectional area of yarns on the cross-section of the hose $\left(A_{a e}\right)$ and the cross-sectional area of the hose $\left(A_{h c}\right)$. The aggregate average end sectional area of yarns is (regarding 269 yarns):

$$
A_{a e}=163.15 \mathrm{~mm}^{2}
$$

Cross-sectional area of the hose has been calculated based on the outer $(39.2$ $\mathrm{mm})$ and inner diameters $(32.8 \mathrm{~mm})$. Area of cross-section of the hose is $A_{h c}=361.91 \mathrm{~mm}^{2}$. Therefore fibre volume fraction equals:

$$
V_{f}=\frac{A_{a e}}{A_{h c}}=45 \%
$$

\subsection{Material Properties of Yarn}

For obtaining material properties of the yarn, tensile test curves, provided by the manufacturer, are crucial (Figure 5). In this figure, two force-strain points were

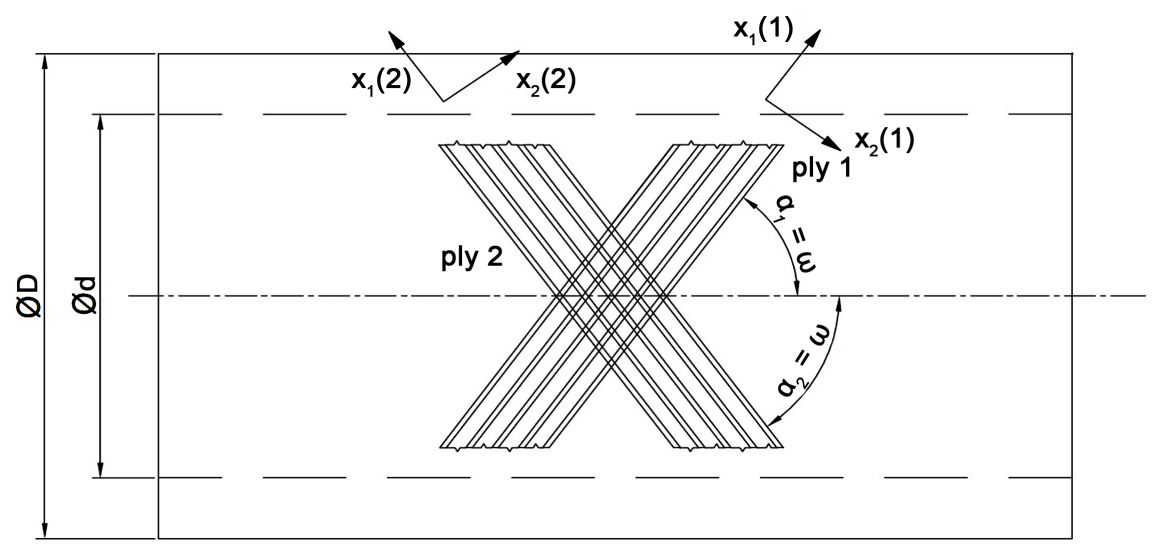

Figure 4. Winding angles (orientation angles) of the composite tube. 


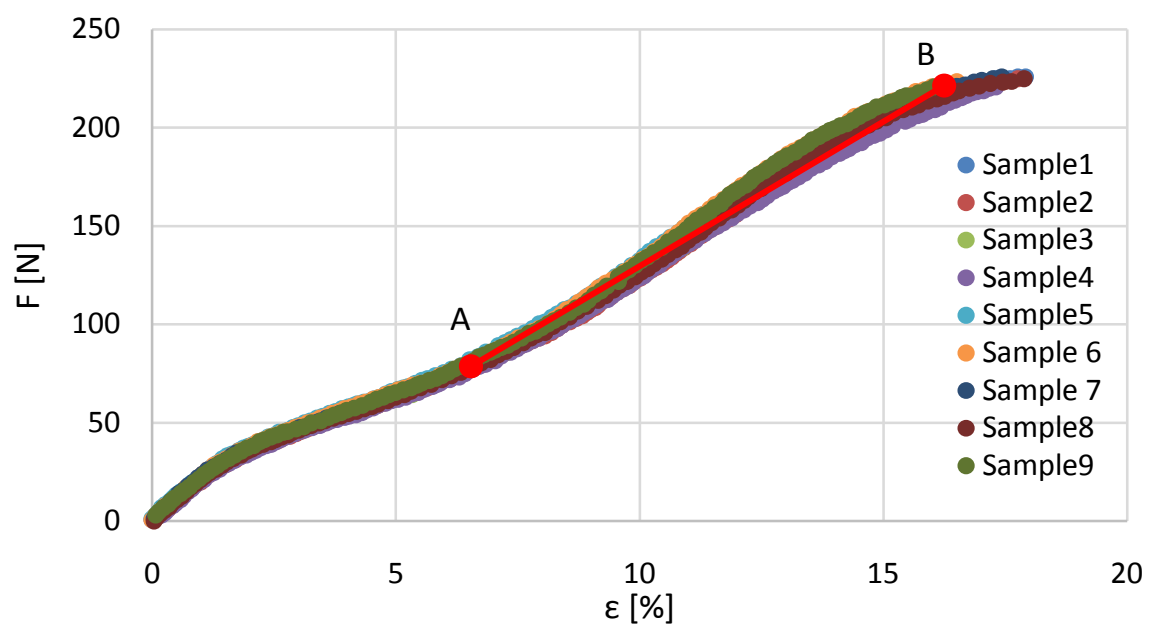

Figure 5. Load-strain curves of a single reinforcement yarn (provided by the manufacturer).

selected (estimated approximate inflexion points, $\mathrm{A}$ and $\mathrm{B}$ ), between which a line can be fitted for gaining characteristic stresses and therefore modulus of elasticity of yarn.

In actual practice of tensile testing, stress-strain curves can be used as a basis for acquiring modulus of elasticity of the fibre. By fitting a line to the load-strain curves and calculating stress values at these points, modulus of elasticity can be obtained by a simplified approach. With the help of the cross-sectional area of yarn $\left(A_{c}=0.496 \mathrm{~mm}^{2}\right)$ and force and strain values of point $\mathrm{A}$ and $\mathrm{B}\left(F_{\mathrm{A}}=78.57 \mathrm{~N}\right.$, $F_{B}=221.4 \mathrm{~N}$ and $\left.\varepsilon_{A}=0.0654, \varepsilon_{B}=0.163\right)$, the calculated stress values are: $\sigma_{A}=158.1 \mathrm{MPa}, \sigma_{B}=446 \mathrm{MPa}$; the modulus of elasticity of the fibre is:

$$
E_{f}=\frac{\sigma_{B}-\sigma_{A}}{\varepsilon_{B}-\varepsilon_{A}}=2961 \mathrm{MPa}
$$

$\sigma_{B}=446 \mathrm{MPa}$ is considered as the tensile strength of the yarn and $\varepsilon_{B}=0.16$ as the elongation at break.

\subsection{Material Properties of Rubber Liners}

Material properties of rubber liners have been determined based on the curve fitted [14] to the uniaxial stress-strain curves provided by the manufacturer. The mechanical model of the rubber liners is 2 parameter Mooney-Rivlin hyperelastic model (Figure 6).

Mooney-Rivlin-parameters of rubber liners are:

$$
C_{10}=-0.4982 \mathrm{MPa}, C_{01}=1.523 \mathrm{MPa}
$$

$D=0[1 / \mathrm{MPa}]$, so rubber liners are assumed to be incompressible in the FE model.

Equivalent shear modulus, Poisson's ratio and modulus of elasticity of rubber liners are:

$$
G_{r}=2 \cdot\left(C_{10}+C_{01}\right)=2.05 \mathrm{MPa}
$$




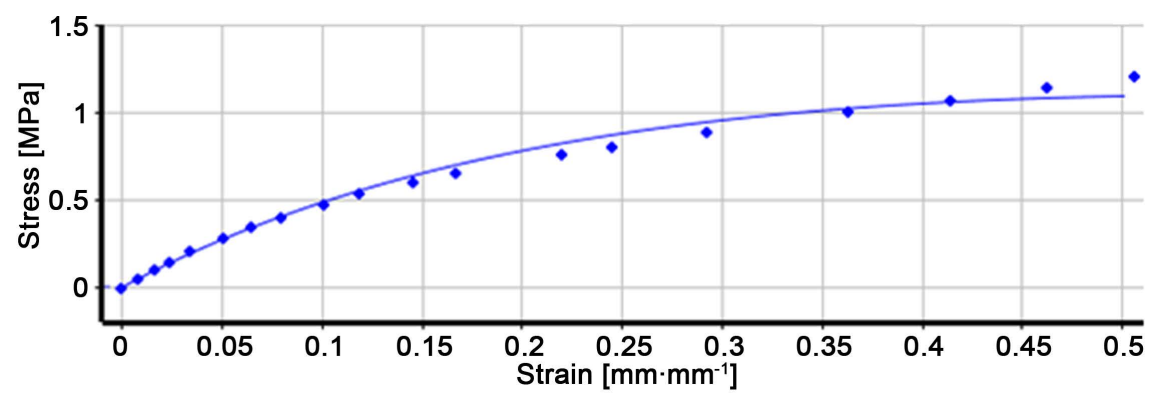

Figure 6. Two parameter Mooney-Rivlin model fitted to uniaxial test data provided by manufacturer.

$$
\begin{gathered}
v_{r}=0.5 \\
E_{r}=2 \cdot\left(1+v_{r}\right) \cdot G_{r}=6.15 \mathrm{MPa}
\end{gathered}
$$

\subsection{Deriving Composite Elastic Constants}

In the most general case, stress and strain states of composites can be described by an anisotropic material model. However, this requires 21 independent elastic constants the measurement of which is often too hard to achieve. Therefore, in most cases, the highest order of symmetry possible is taken into consideration. Firstly, composite parts are generally considered to be described as orthotropic having three mutually perpendicular planes of symmetry; filament-wound composite hoses, with their fibres aligned uniaxially, are usually regarded as transversely isotropic because the plane perpendicular to the fibre direction is a plane of isotropy $\left(E_{2}=E_{3}, G_{12}=G_{13}, v_{12}=v_{13}\right)$. Transversely isotropic materials have five independent elastic constants $\left(E_{1}, E_{2}, G_{12}, G_{23}, v_{12}\right)$ [15].

Modulus of elasticity of the matrix is $E_{m}=E_{r}=6.15 \mathrm{MPa}$, its Poisson's ratio is supposed to be $v_{m}=v_{r}=0.5$. Poisson's ratio of the fibre is assumed to be $v_{f}=0.2$. Fibre volume fraction is $V_{f}=45 \%$.

Matrix volume fraction and shear modulus of fibre are respectively as follows:

$$
\begin{aligned}
& V_{m}=1-V_{f}=1-0.45=0.55 \\
& G_{f}=\frac{E_{f}}{2 \cdot\left(1+v_{f}\right)}=1234 \mathrm{MPa}
\end{aligned}
$$

Modulus of elasticity of one ply in direction 1 is:

$$
E_{1}=E_{f} \cdot V_{f}+E_{m} \cdot V_{m}=1338 \mathrm{MPa}
$$

Applying the formulae presented in [15] and [16], the modulus of elasticity in directions 2 and 3 and shear moduli are:

$$
\begin{gathered}
E_{2}=E_{3}=\frac{E_{m}}{1-\sqrt{V_{f}} \cdot\left(1-E_{m} / E_{f}\right)}=19 \mathrm{MPa} \\
G_{12}=G_{13}=G_{23}=\frac{G_{m}}{1-\sqrt{V_{f}} \cdot\left(1-G_{m} / G_{f}\right)}=6 \mathrm{MPa}
\end{gathered}
$$

Since $G_{f 12}=G_{f 23}$, apparently $G_{12}=G_{23}$. 
Poisson's ratios of one ply are [12]:

$$
v_{12}=v_{13}=V_{f} \cdot v_{f}+V_{m} \cdot v_{m}=0.37
$$

Contraction in plane 23 is principally governed by the mechanical behaviour of rubber, so

$$
v_{23}=\frac{E_{22}}{2 \cdot G_{23}}-1=0.498
$$

\section{Tensile Experiment on Standard Test Specimen Cut from the Hose}

Test specimen used for uniaxial tension test has been cut from the hose in thickness direction in accordance with standard ASTM D638. The specimen, having a length of $75 \mathrm{~mm}$, has been tested to complete failure. The experiment began with a pre-load of $1 \mathrm{~N}$ with a pre-load speed of $2 \mathrm{~mm} / \mathrm{min}$. The test was executed on a Zwick Z250 tensile testing machine with a tensile speed of 2 $\mathrm{mm} / \mathrm{min}$. The measuring limit of the load cell was $10 \mathrm{kN}$.

Firstly, fractures appeared in reinforcement plies, which led to yarn-matrix debonding. This may be attributed to yarns aligning themselves to the direction of load generating shear inside plies (Figure 7). As the tension progressed, gaps appeared between the two rubber liners.

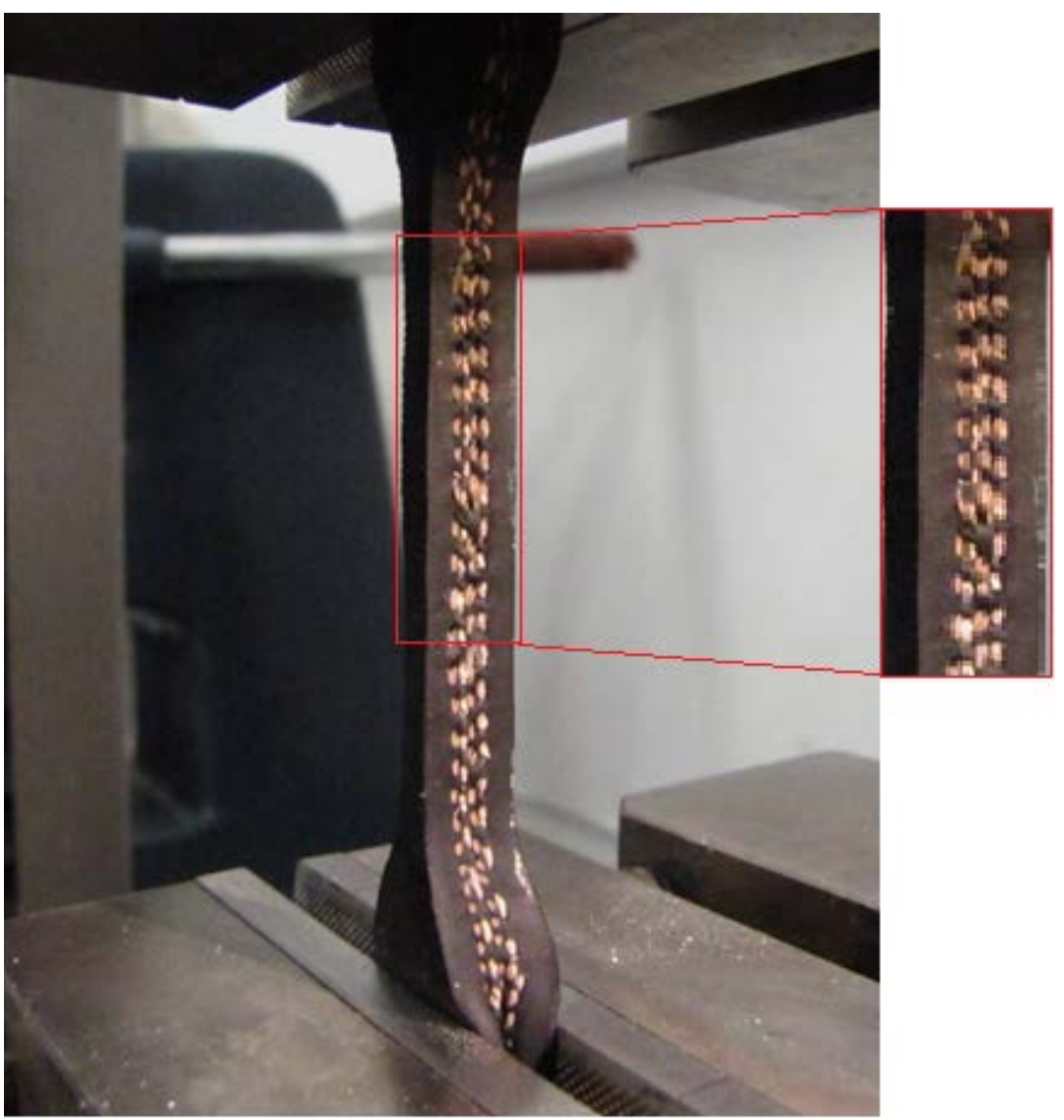

Figure 7. Tensile test specimen at a displacement of $19 \mathrm{~mm}$. 


\section{Finite Element Analysis of the Uniaxial Tension Test on Test Specimen}

Finite element analysis of tensile test on standard test specimen consists of two separate sections, the first being the representation of fastening the specimen, while the second part simulates uniaxial tension.

\subsection{Geometric Model}

Inner diameter of the specimen is $28 \mathrm{~mm}$, outer diameter is $44 \mathrm{~mm}$, and thickness of the rubber liners equals $2.4 \mathrm{~mm}$. There are 4 reinforcement plies consisting of natural yarns and rubber matrix. The material coordinate systems of the plies are cylindrical, the layup is $[+55 /-55 /+55 /-55]\left[{ }^{\circ}\right]$ with respect to the axis of the hose based on technical specification provided by the manufacturer (Figure 8).

Geometry of the specimen can be observed in Figure 9 along with the dimensions and the fibre orientation of ply 1 (its orientation angle is $\omega=+55^{\circ}$ ).

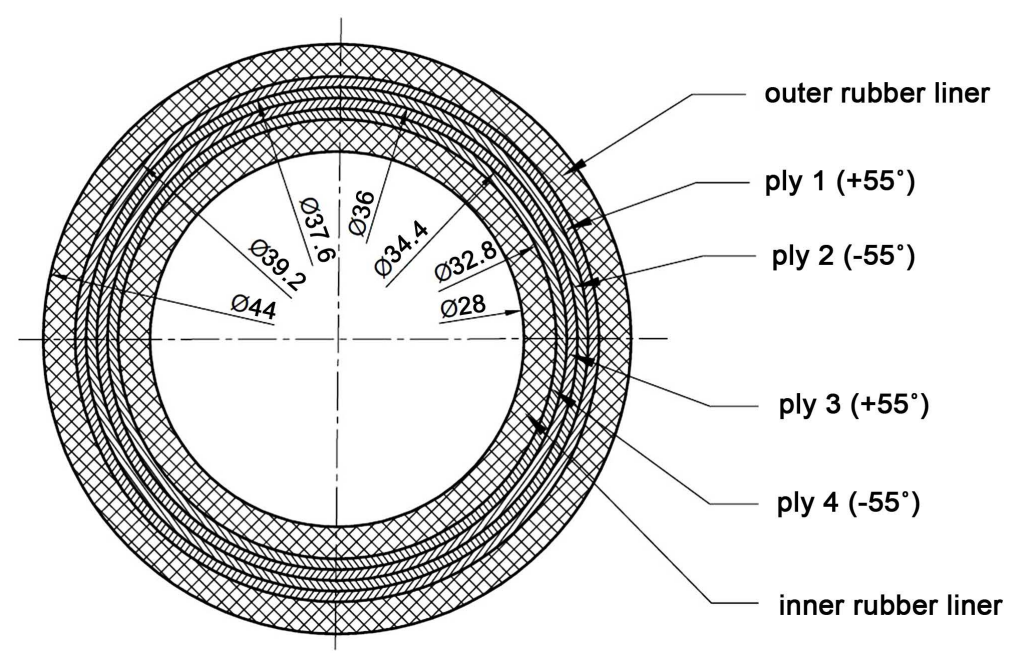

Figure 8. Cross-section of the hose.

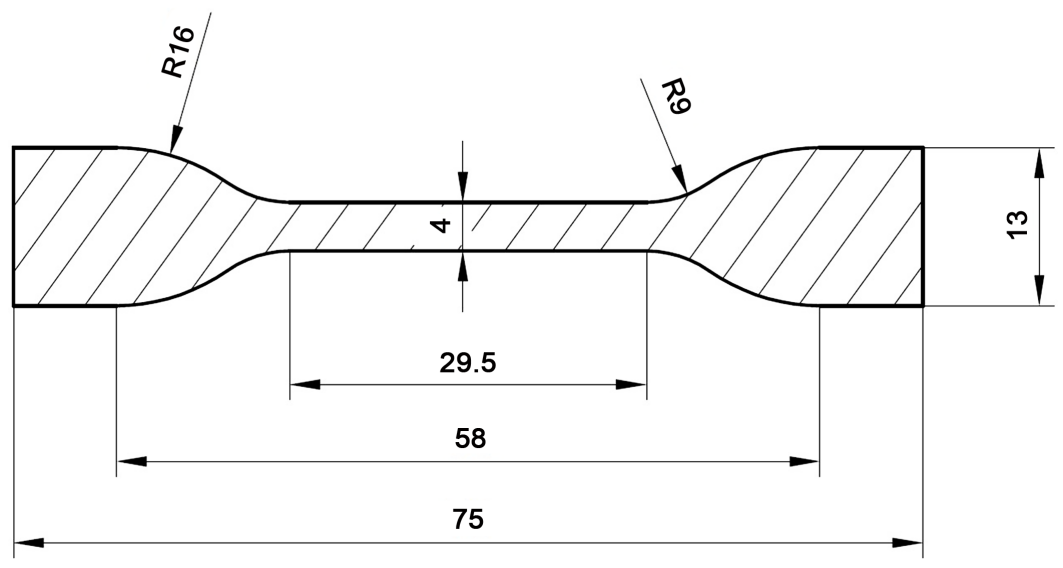

Figure 9. Dimensions of the test specimen, along with the fibre orientation of ply1 $\left(+55^{\circ}\right)$. 


\subsection{Connections}

There are bonded contacts between the reinforcement plies and the outer rubber liner and the reinforcement plies and the inner rubber liner respectively because rubber, being the material of the matrix and also material of inner and outer liners, is vulcanized around yarns. The contacts defined between the rubber liners and the tensile jaws are frictional with a coefficient of friction $\mu=0.8$ based on [17], and formulation “Augmented Lagrange".

\subsection{Mesh}

Finite element mesh (Figure 10) consists of approximately 14,800 nodes and 13,100 elements.

\subsection{Loads, Boundary Conditions}

The simulation consists of three time steps. In the first and the second one, test specimen is installed between the tensile jaws, in the third time step, tension is applied to the specimen.

In the first time step, the upper tensile jaw at the right end descends $-2 \mathrm{~mm}$ in $\mathrm{Y}$ direction, while the lower tensile jaw opposite of the former stands still (Figure 11).

In the second time step, left end of the specimen is being fixed. The upper tensile jaw sinks $-2 \mathrm{~mm}$ in $\mathrm{Y}$ direction, while the lower tensile jaw is fixed.

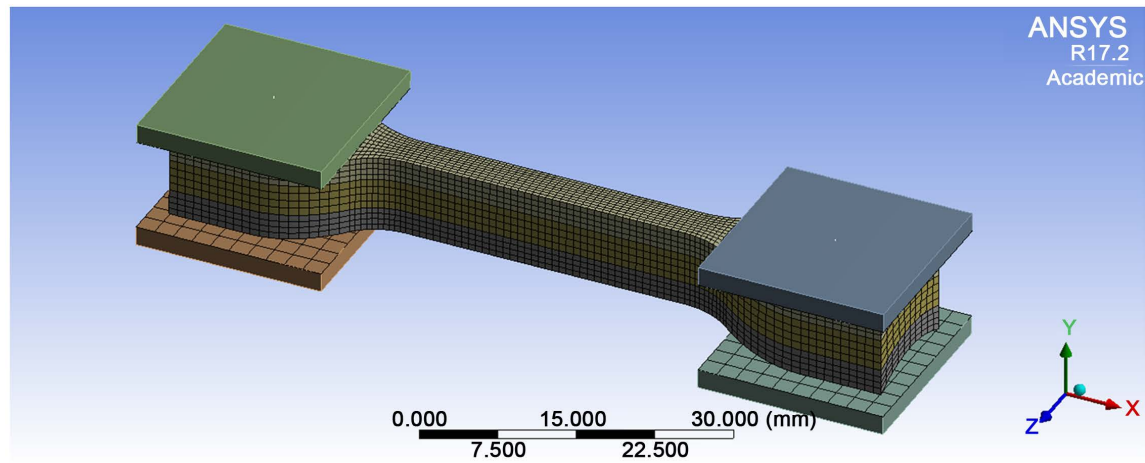

Figure 10. Finite element mesh.

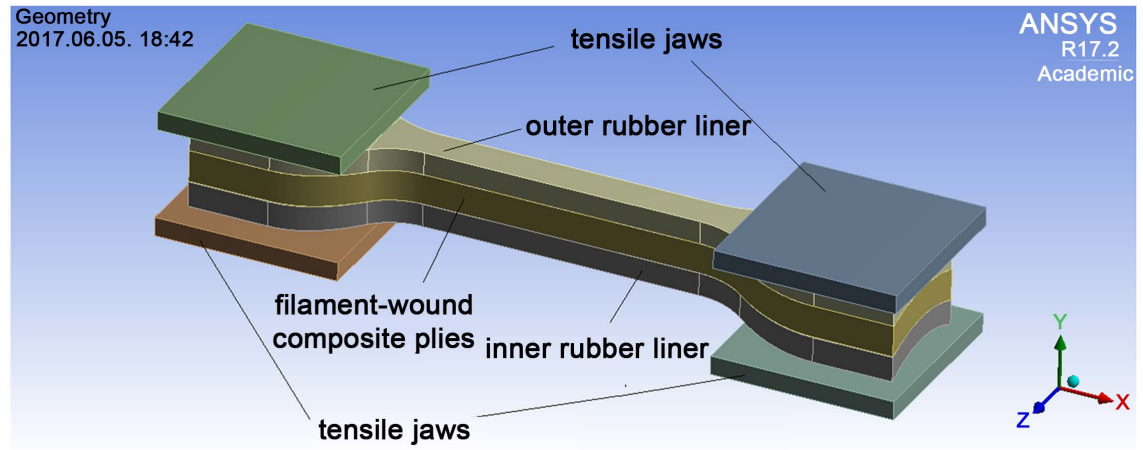

Figure 11. Disposition of the finite element model. 
Meanwhile, the upper right tensile jaw holds its position $-2 \mathrm{~mm}$ from its initial horizontal position and the lower right tensile jaw is still fixed. In the third time step, tensile jaws situated at the right end are subjected to a prescribed displacement of $25 \mathrm{~mm}$ in positive $\mathrm{X}$ direction. In the meantime, tensile jaws situated at the left end hold their position.

\subsection{Material Properties}

Material model of the reinforcement plies is linear orthotropic, the corresponding material properties can be found in Chapter 2.4. The rubber liners surrounding the reinforcement plies are described by a 2 parameter Mooney-Rivlin model, its parameters defined in Chapter 2.3.

\subsection{Results of the Simulation of Tensile Test on Tensile Specimen}

Results of finite element analysis of uniaxial tension of tensile specimen at a displacement of $25 \mathrm{~mm}$ are disclosed below.

Elongation in the global coordinate system at the end of the third time step is significant in the whole cross-section, approximately $\varepsilon_{\mathrm{x}}=0.5$ (Figure 12).

Stress and strain results, being true stress and true strain results, regarding ply 1 are hereinafter presented, afterwards, mean values are disclosed for each ply in tables. Stress and strain results in ply 1 are to be considered based on the material orientation of Figure 9.

Figure 13 shows normal strain distribution in material direction 1 (fibre direction) in fibre coordinate system for ply 1 at a prescribed displacement of 25 $\mathrm{mm}$. The strain distribution tends to be uniform between the necks, while near the necks, it represents the material orientation of the ply. Strain values are low because of the high longitudinal modulus of elasticity, $E_{1}=1338 \mathrm{MPa}$.

As regards other components of strain in the plane of ply1, normal strain in material direction 2 and shear strain in plane 12 have the same distribution as presented in Figure 14.

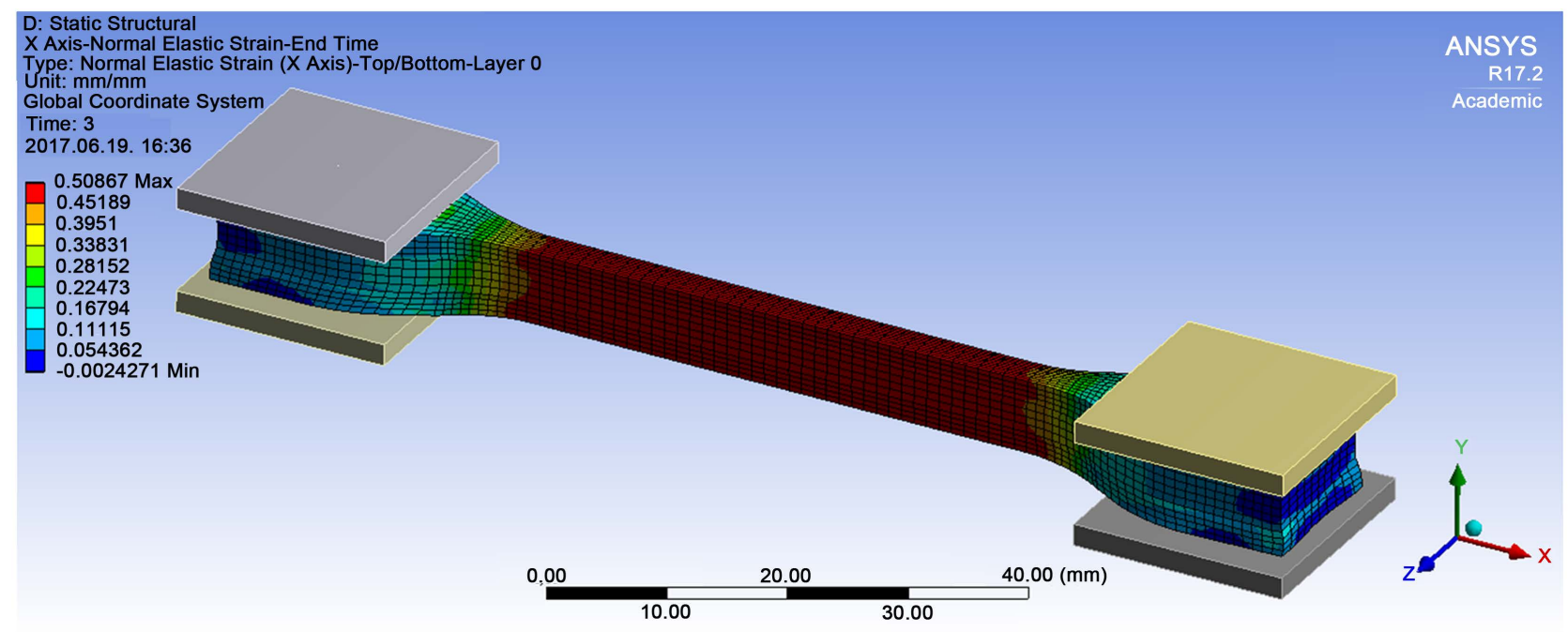

Figure 12. Elongation at a prescribed displacement of $25 \mathrm{~mm}\left(\varepsilon_{\mathrm{x}}\right)$ in the global coordinate system. 


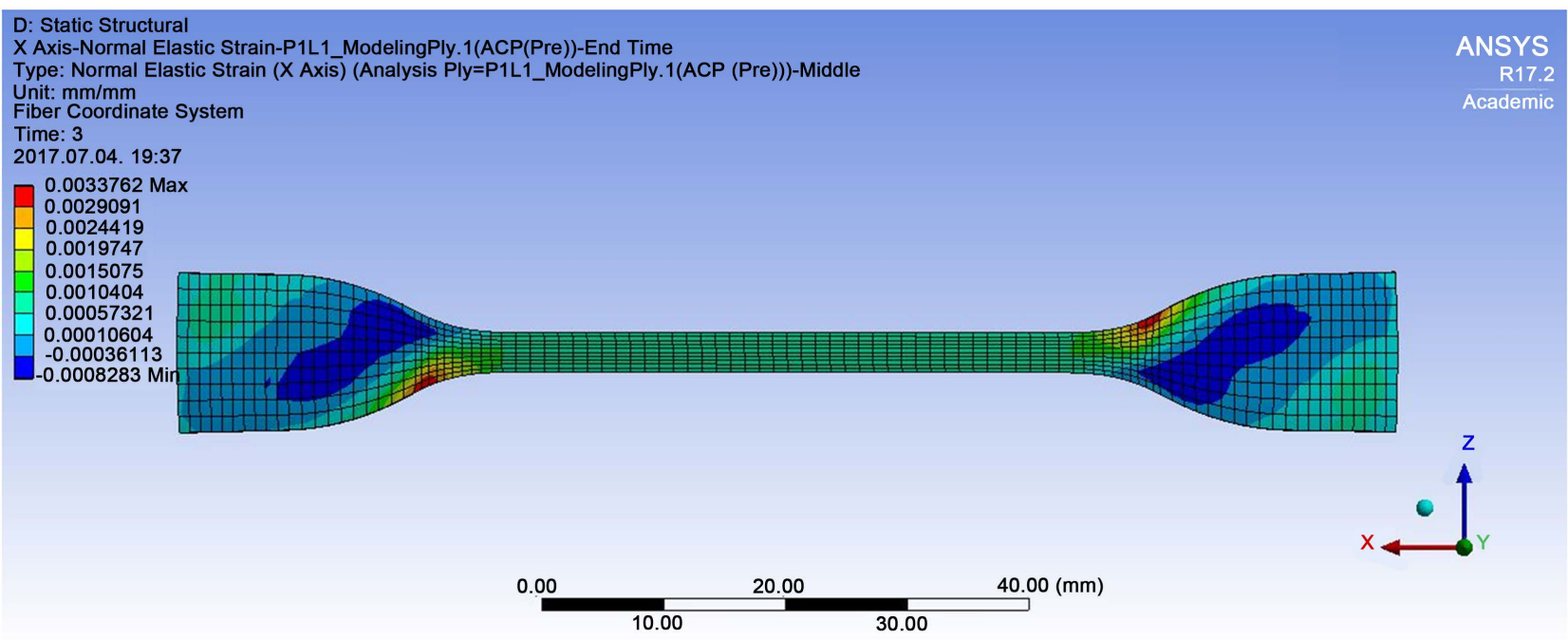

Figure 13. Normal strain in material direction $1\left(\varepsilon_{1}\right)$ in fibre coordinate system, ply 1.

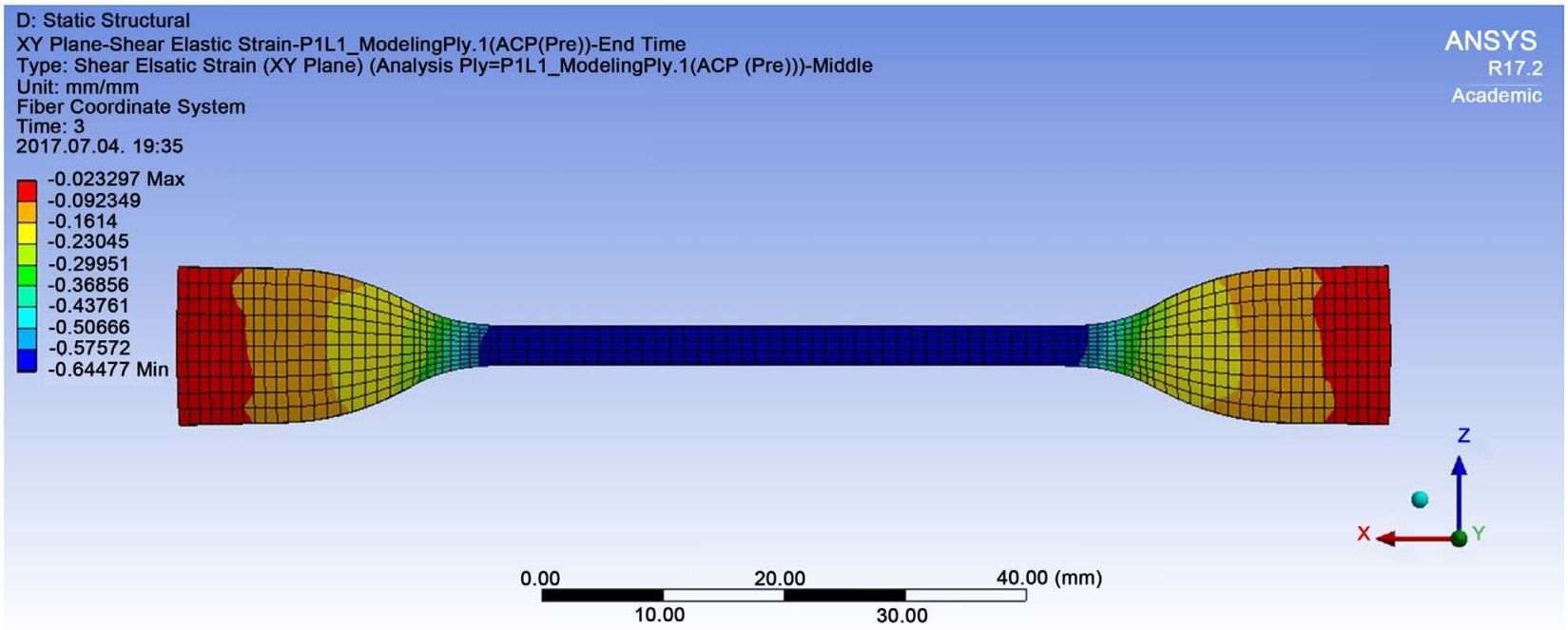

Figure 14. Shear strain in plane $12\left(\gamma_{12}\right)$ in fibre coordinate system, ply 1 .

The predominant strain component is shear strain (Figure 14), whose absolute value is approximately the same for every ply, however sign of shear strains is opposite in adjacent plies, which can be attributed to the balanced layup (Table 1). The reason why the shear stress is so significant is that load is off-axis regarding the material orientation in each ply. The significant shear stress results in high shear strain considering fairly low shear moduli.

Average strains with the exception of longitudinal strains in the fibre coordinate system are considerable; Table 1 indicates that global longitudinal strain is transformed primarily to transverse normal strain and shear strain in the fibre coordinate system.

Figure 15 shows distribution of longitudinal stresses in the global coordinate system. Highest stress values can be recognized in reinforcement layers, while nearly one third of the peak value is present in rubber liners, so reinforcement plies are considered to be the load-bearing components. 


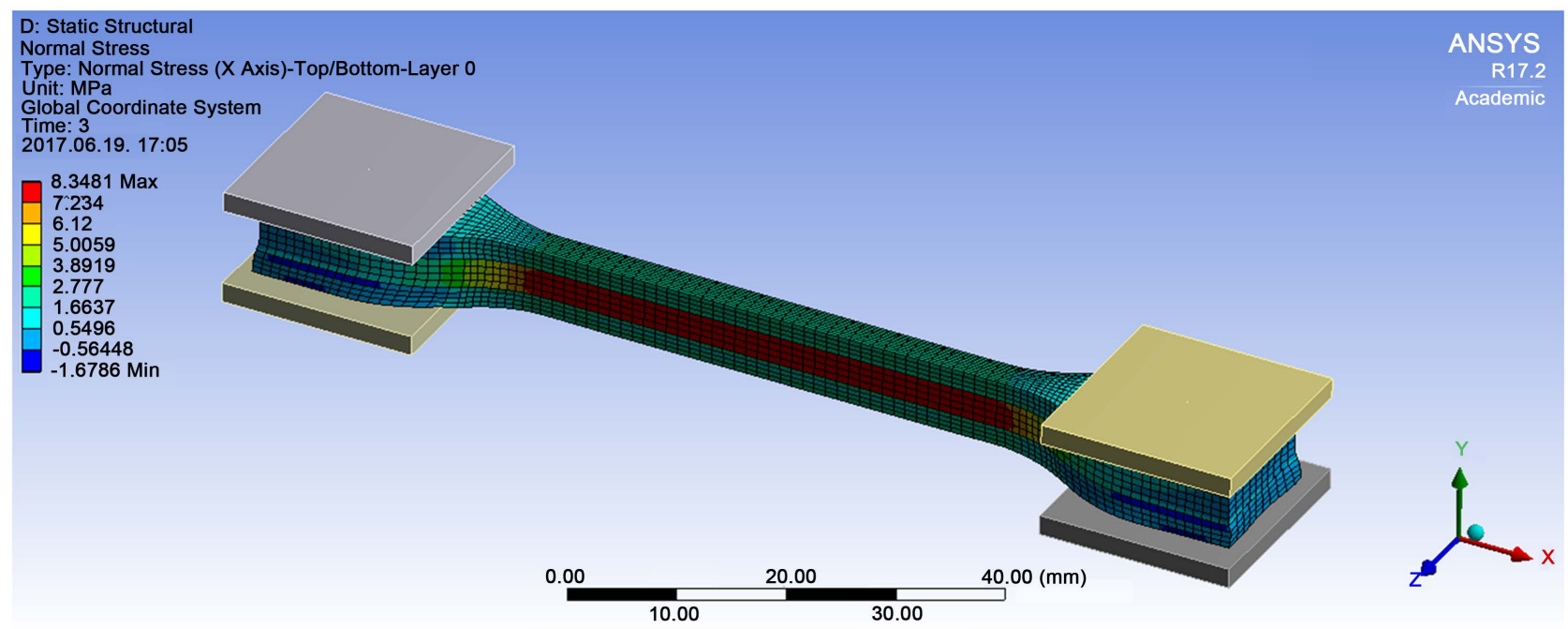

Figure 15. Longitudinal stress $\left(\sigma_{\mathrm{x}}\right)$ at a displacement of $25 \mathrm{~mm}$ in the global coordinate system.

Table 1. Average strains in reinforcement plies in the vertical midplane.

\begin{tabular}{ccccc}
\hline ply no. & $\varepsilon_{\mathrm{x}}[-]$ & $\varepsilon_{1}[-]$ & $\varepsilon_{2}[-]$ & $\gamma_{12}[-]$ \\
\hline 1 & 0.4665 & 0.001 & 0.2493 & -0.6349 \\
2 & 0.4663 & 0.0015 & 0.2385 & 0.6504 \\
3 & 0.4663 & 0.0016 & 0.2386 & -0.6504 \\
4 & 0.4664 & 0.0009 & 0.2488 & 0.6359 \\
\hline
\end{tabular}

Normal stress distribution in material direction 1 in fibre coordinate system is identical to normal strain distribution in the same direction; normal stress values (Figure 16) are considerable. Shear stress (Figure 17) tends to be the predominant stress component along with transverse normal stress $\left(\sigma_{2}\right)$ having the same distribution.

Average stress values can be observed in Table 2. The maximum values can be found in ply 2 and ply 3 for every stress component; however the stress variance in the direction normal to each ply tends to be slight. Sign of shear strains is opposite in adjacent plies, because the layup is balanced, similarly as in case of strains.

\subsection{Reviewing the Results}

At the end of tension, longitudinal stress in the reinforcement plies at a displacement of $25 \mathrm{~mm}$ is approximately $8 \mathrm{MPa}$ (Figure 18) in the global coordinate system. Aggregate cross-sectional area of the reinforcement plies is $9 \mathrm{~mm}^{2}$ (width: $3.1 \mathrm{~mm}$, height: $2.9 \mathrm{~mm}$ ). The respective average longitudinal stress value for the rubber liners is $1.9 \mathrm{MPa}$. Total cross-sectional area of rubber liners equals $11.8 \mathrm{~mm}^{2}$ (width: $3.1 \mathrm{~mm}$, height: $1.9 \mathrm{~mm}$ ). Hence, the force exerted to the cross section is $94.3 \mathrm{~N}$. Reaction force queried at this load step is $93.57 \mathrm{~N}$.

Figure 19 illustrates experimental data and simulation results of tensile test as force-displacement curves. There is good agreement between finite element re- 


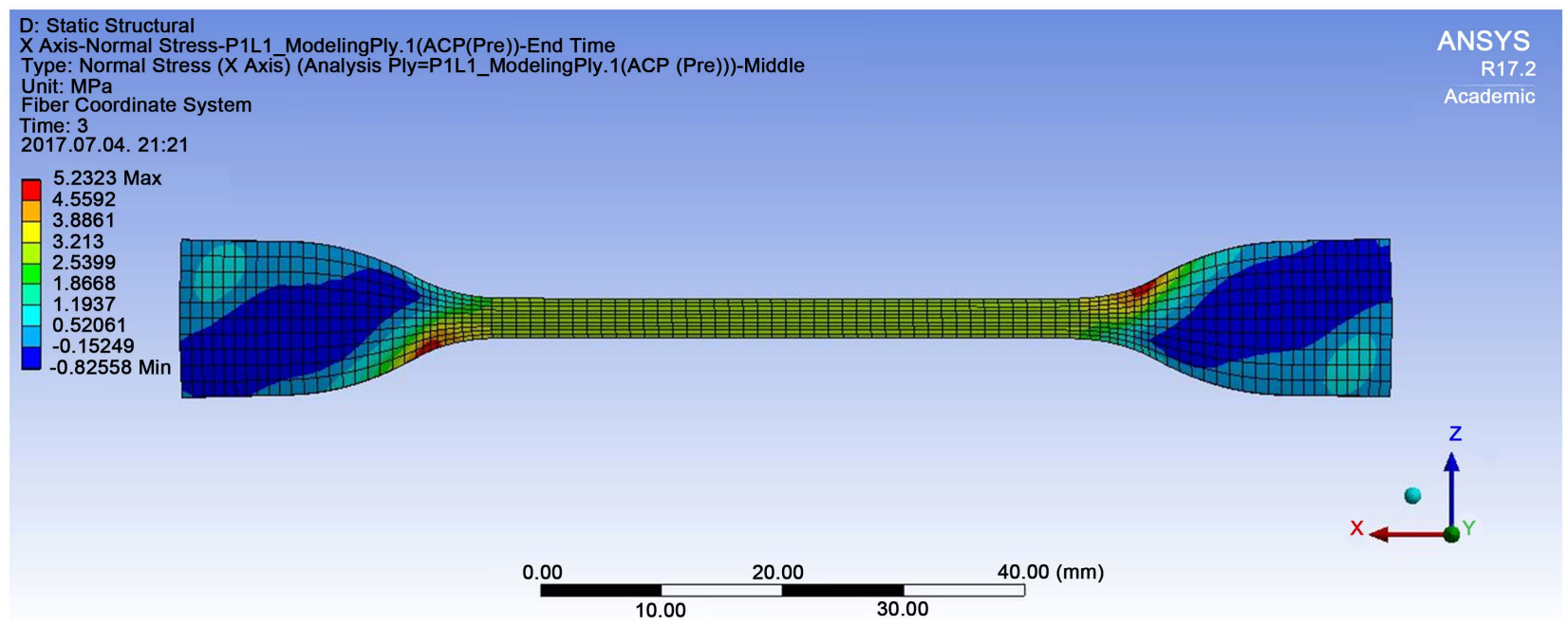

Figure 16. Normal stress in material direction $1\left(\sigma_{1}\right)$ in fibre coordinate system, ply 1.

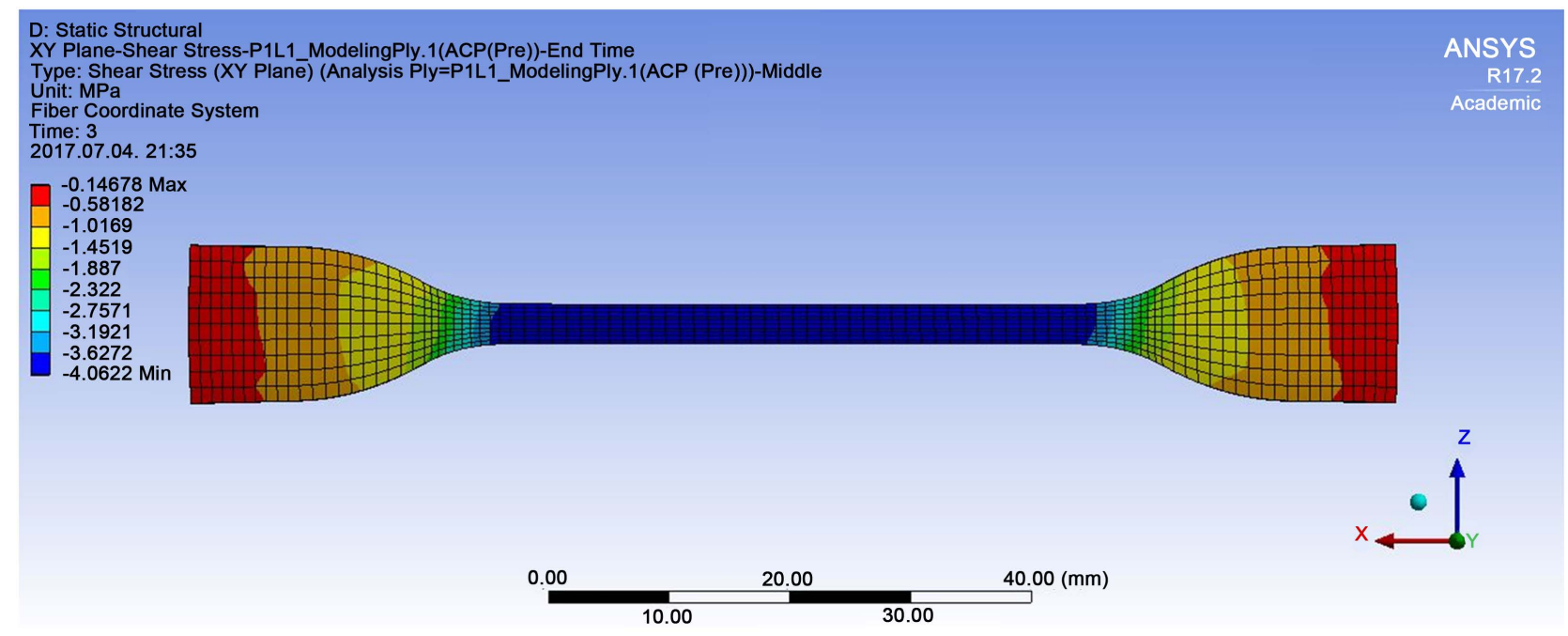

Figure 17. Shear stress in plane $12\left(\tau_{12}\right)$ in fibre coordinate system, ply 1.

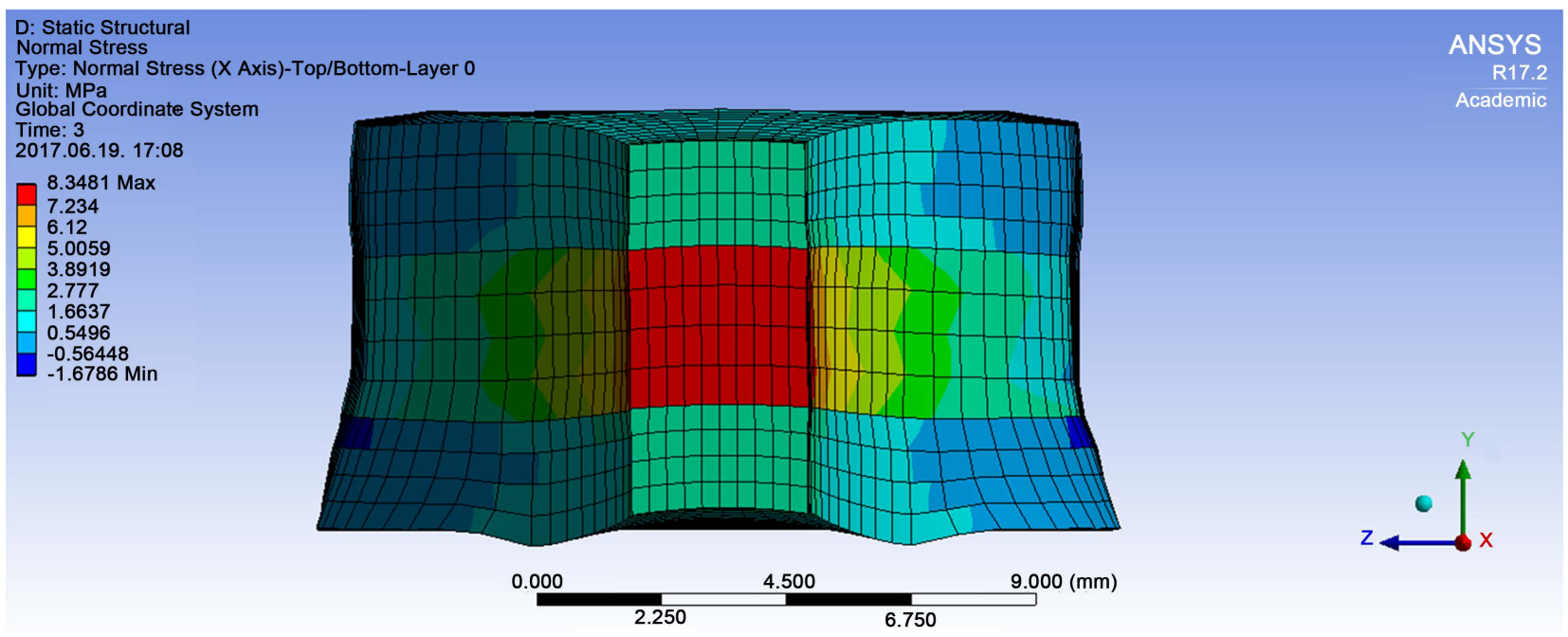

Figure 18. Longitudinal stress $\left(\sigma_{\mathrm{x}}\right)$ in the cross-section in the global coordinate system at a displacement of $25 \mathrm{~mm}$. 


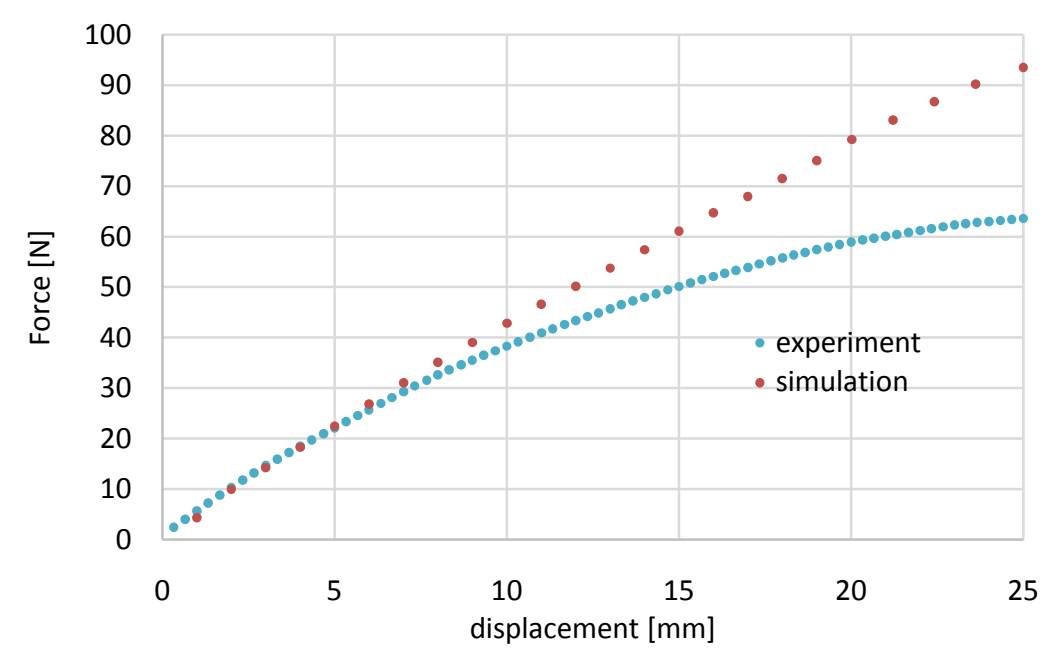

Figure 19. Force-displacement curves of standard test specimen.

Table 2. Average stresses in reinforcement plies in the vertical midplane.

\begin{tabular}{ccccc}
\hline ply no. & $\sigma_{\mathrm{x}}[\mathrm{MPa}]$ & $\sigma_{1}[\mathrm{MPa}]$ & $\sigma_{2}[\mathrm{MPa}]$ & $\tau_{12}[\mathrm{MPa}]$ \\
\hline 1 & 7.88 & 2.95 & 4.67 & -4.09 \\
2 & 8.05 & 3.68 & 4.46 & 4.1 \\
3 & 8.06 & 3.69 & 4.46 & -4.1 \\
4 & 7.86 & 2.91 & 4.66 & 4 \\
\hline
\end{tabular}

sults and experimental data in the initial section of the force-displacement curves regarding the operating range. However, after a displacement of $10 \mathrm{~mm}$, in the course of the failure procedure, substantial difference can be noticed between experimental and simulation results because failure mechanisms are not taken into account in the FE model.

\section{Tensile Test Experiment of Hose Piece}

Tensile test of a hose piece having length of $110 \mathrm{~mm}$ was performed (Figure 20) to a displacement of $25 \mathrm{~mm}$. Cross-section of the hose piece is in accordance with Figure 8. Uniaxial tension was realized with the help of two steel plugs fixed into the hose by pipe clamps and by bonding them to the inner liner of the hose.

Hose piece was pulled with a speed of $2 \mathrm{~mm} / \mathrm{min}$ and a preload of $1 \mathrm{~N}$. Tensile tests were performed three times.

\section{Finite Element Model of the Uniaxial Tension of Hose Piece}

\subsection{Connections}

There are bonded contacts between the reinforcement plies and the outer rubber liner and the reinforcement plies and the inner rubber liner respectively. The plugs are connected to the inner lateral surface of the hose by bonded contacts. 


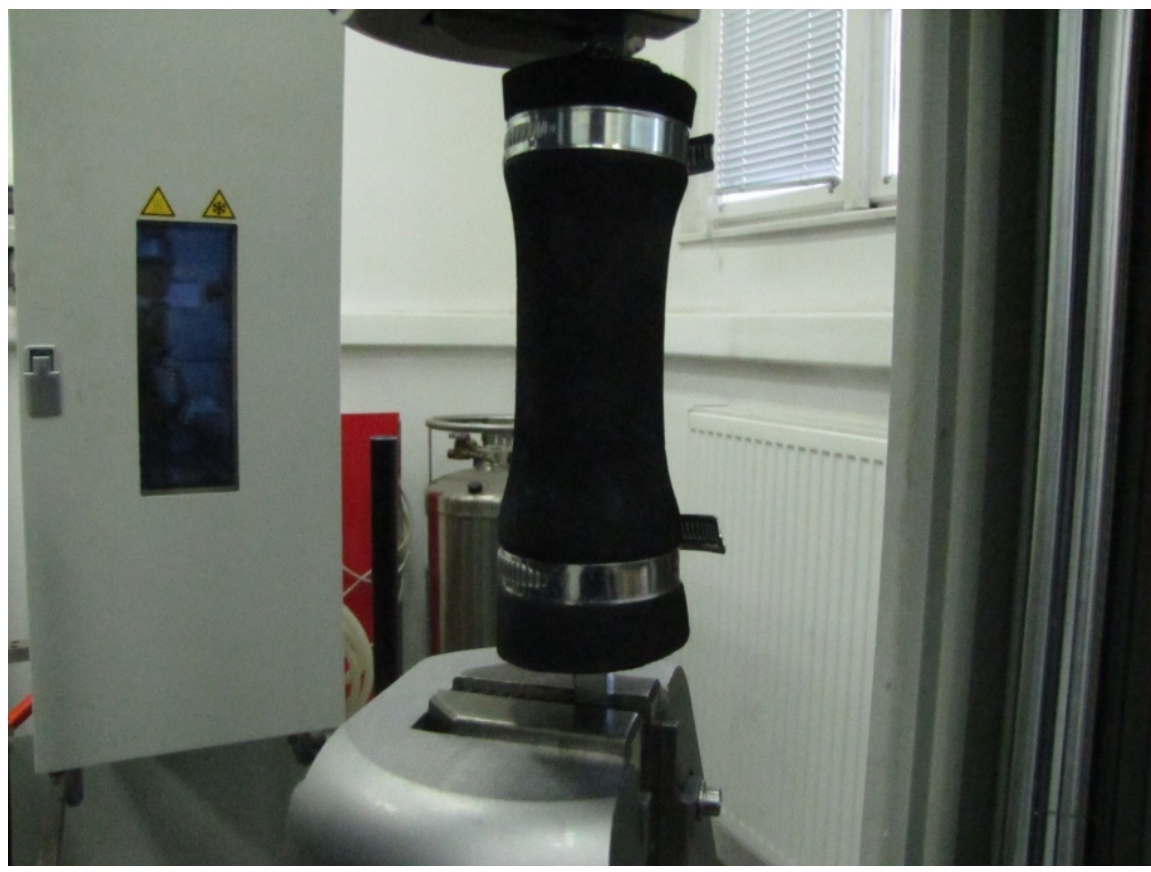

Figure 20. Hose piece subjected to tensile load at a displacement of $25 \mathrm{~mm}$.

\subsection{Mesh}

Mesh of the finite element hose piece model, being a three-dimensional full model, consists of nearly 25,100 nodes and 21,000 elements (longitudinal section illustrated in Figure 21). Reinforcement plies are represented by 4 adjacent layers of elements between 3 layers representing outer rubber liner and 3 layers representing inner rubber liner.

\subsection{Loads, Boundary Conditions}

In the first time step, pressure of $1.5 \mathrm{MPa}$, which represents pipe clamps, is applied to sections of the outer side surface of the hose shown in Figure 22.

In the second time step, a prescribed displacement of $25 \mathrm{~mm}$, being in line with the prescribed boundary condition of the test, is applied to the right end of the right plug. Meanwhile, the left end of the left plug is fixed.

\subsection{Material Properties}

Material properties of the reinforcement plies, presented in detail in Chapter 2.4, and rubber liners, presented in detail in Chapter 2.3, are identical to material properties of the test specimen.

Steel plugs utilized for transmitting tensile load to the hose piece are modeled as rigid bodies in the present finite element model.

\section{Results of FE Analysis and Experiment of Tensile Test of Hose Piece}

Figure 23 shows experimental data of uniaxial tension of hose piece with the mean values along with simulation results. 


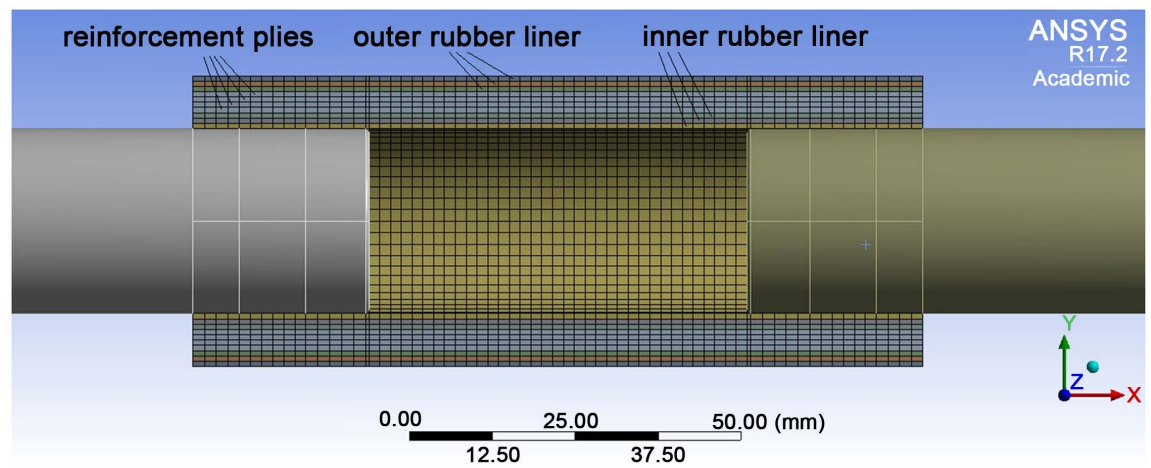

Figure 21. Longitudinal section of the meshed geometry.

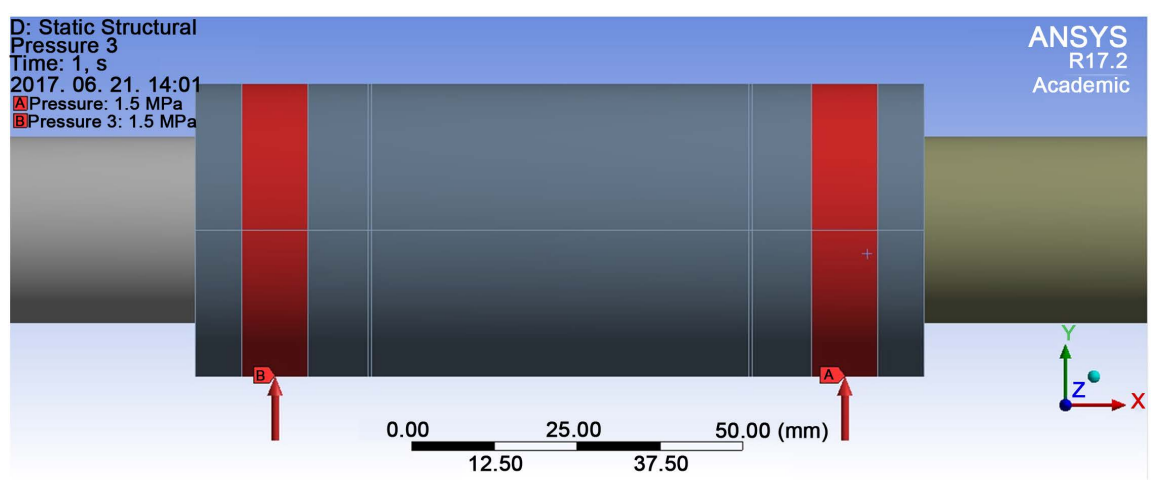

Figure 22. Pressure load representing pipe clamps, 1.5 MPa.

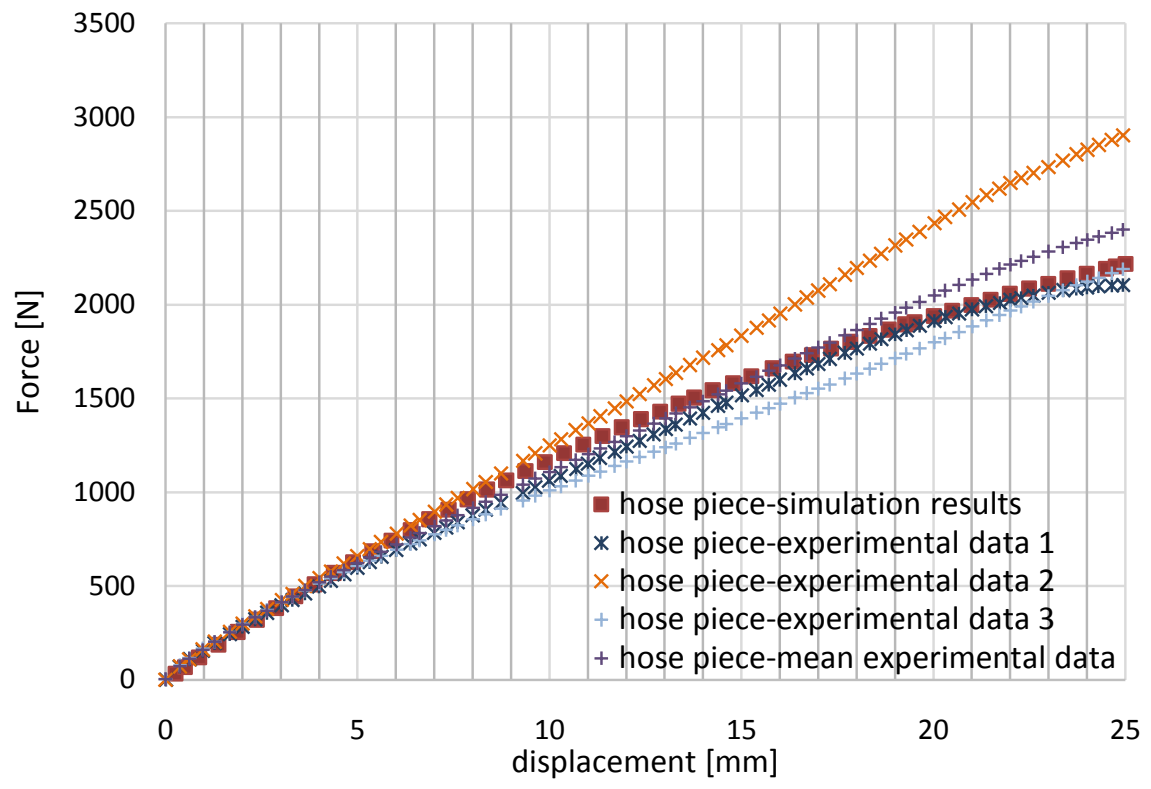

Figure 23. Force-displacement curves of hose piece.

Simulation results and experimental data are in good agreement, difference between simulation results and mean experimental data is less than $10 \%$ of mean experimental data, moreover, simulation results are located between minimum and maximum of experimental data at all data points (Figure 23). 
Deformation, strain and stress results at a displacement of $25 \mathrm{~mm}$ are displayed below.

Hose piece elongates as much as 0.33 (Figure 24) at a displacement of $25 \mathrm{~mm}$, which is considered significant. The deformed shape of Figure 24 is noticeably similar to the deformed shape after tensile testing, shown in Figure 20.

Normal strain in material direction 1 in fibre coordinate system can be observed in Figure 25. These strain values tend to be of low order of magnitude due to high stiffness in material direction 1.

Shear strain in plane 12 shown in Figure 26 has a predominant role in the structural behaviour of hose piece under tension because of the load being off-axis to the fibre direction and shear moduli being relatively low. Normal strain in material direction 2, having the same distribution as shear strain in plane 12 , is also considerably significant (Table 3 ) being the other strain component into which global longitudinal strain is transformed. Strains are almost equally distributed along reinforcement plies.

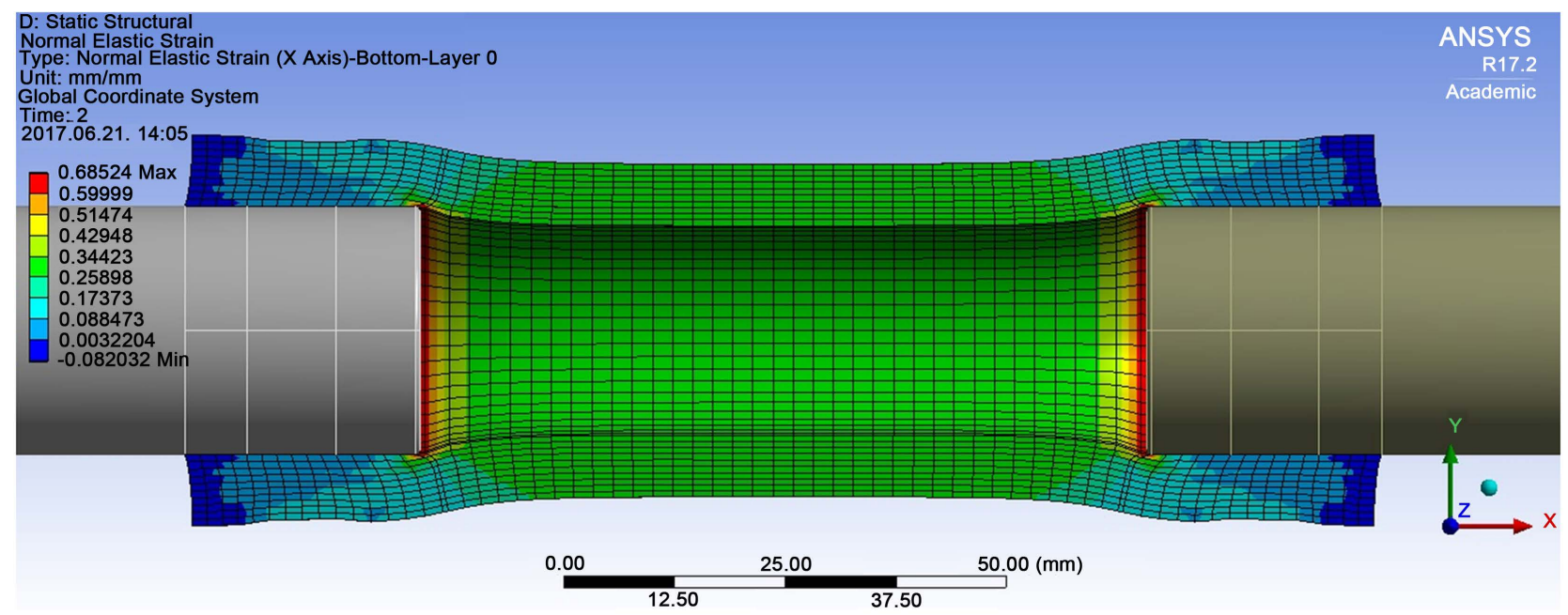

Figure 24. Elongation $\left(\varepsilon_{\mathrm{x}}\right)$ at a prescribed displacement of $25 \mathrm{~mm}$ in the global coordinate system.

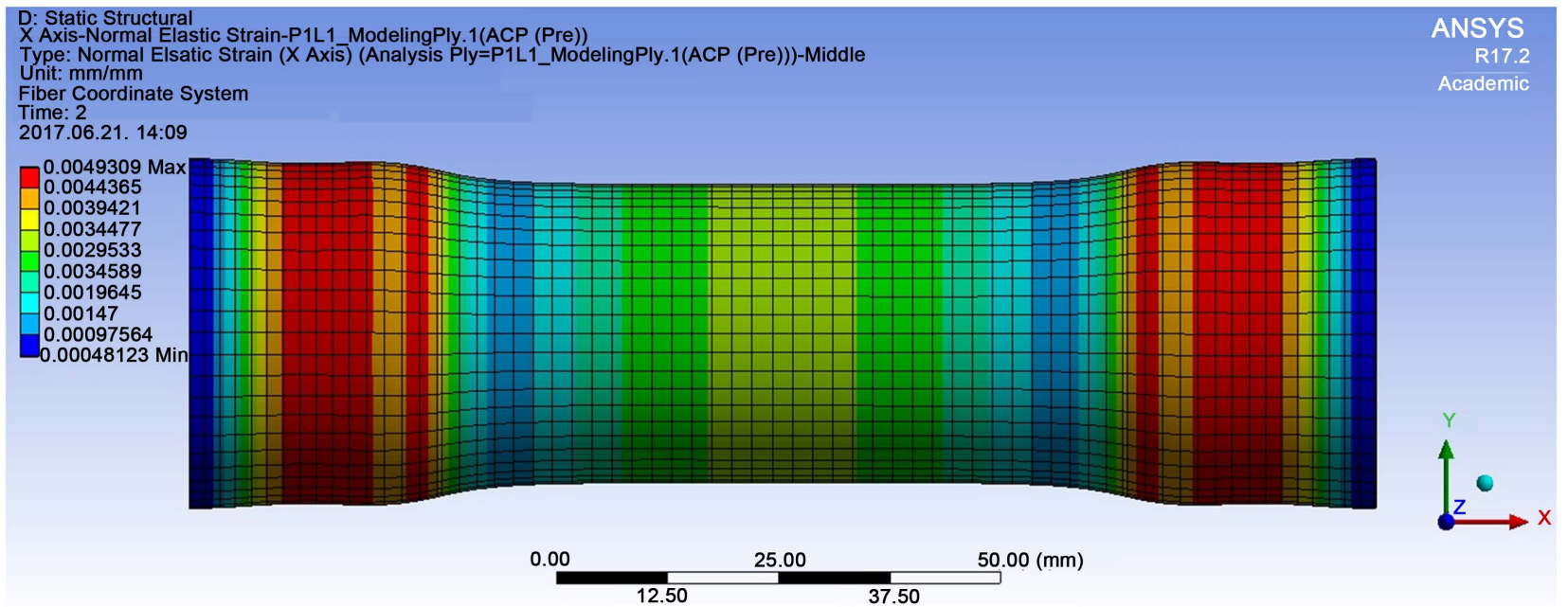

Figure 25. Normal strain in material direction $1\left(\varepsilon_{1}\right)$ in fibre coordinate system, ply 1 . 


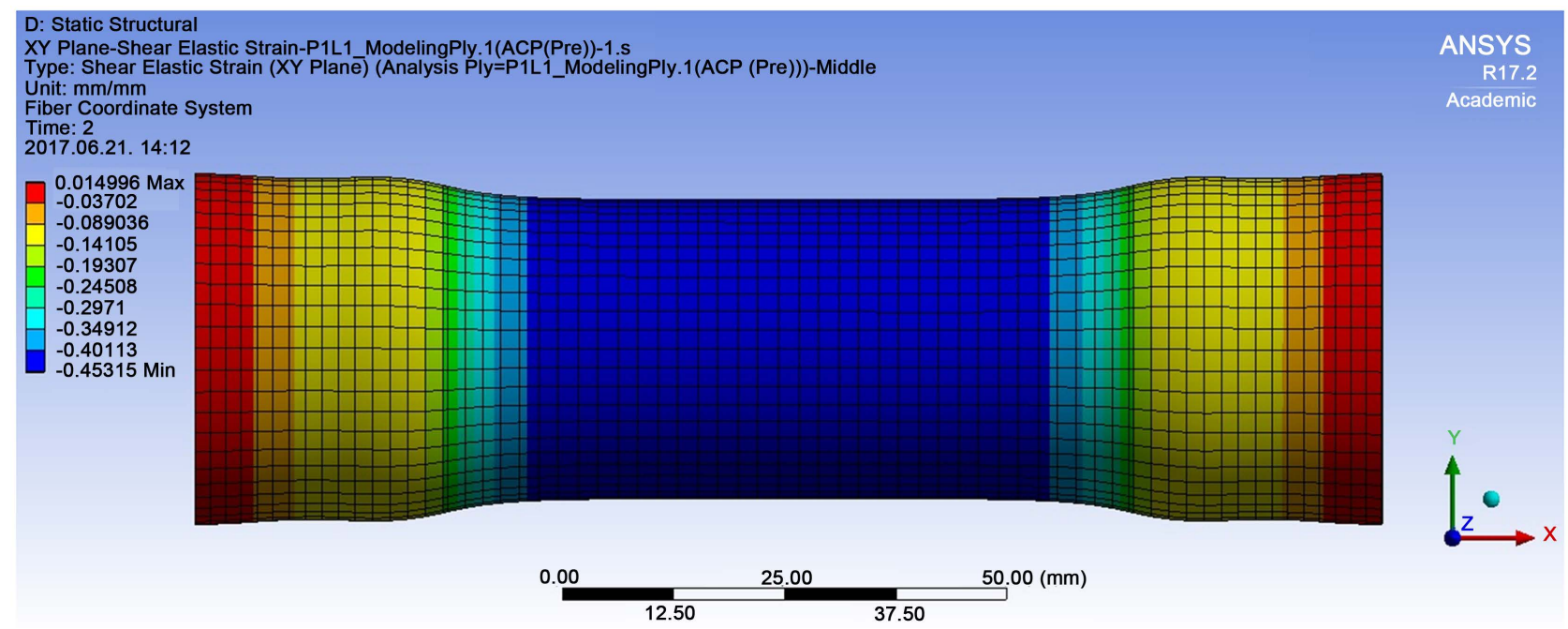

Figure 26. Shear strain in plane $12\left(\gamma_{12}\right)$ in fibre coordinate system, ply 1 .

Table 3. Average strains in reinforcement plies in the vertical midplane.

\begin{tabular}{ccccc}
\hline ply no. & $\varepsilon_{\mathrm{x}}[-]$ & $\varepsilon_{1}[-]$ & $\varepsilon_{2}[-]$ & $\gamma_{12}[-]$ \\
\hline 1 & 0.3276 & 0.003 & 0.1694 & -0.4531 \\
2 & 0.3279 & 0.0024 & 0.1675 & 0.4571 \\
3 & 0.3285 & 0.0006 & 0.1679 & -0.4597 \\
4 & 0.3287 & 0.0018 & 0.1658 & 0.4571 \\
\hline
\end{tabular}

Figure 27 also proves that reinforcement plies are mainly responsible for the load bearing capability of the hose due to high stress values present in them. Local maximum stresses in the hose piece can be found near the contact to the plugs.

Stress distribution is very much alike strain distribution in reinforcement plies, so stresses are presented as average values in Table 4.

Figure 28 illustrates experimental data and simulation results for the hose piece along with experimental data and simulation results for the standard test specimen proportioned to the hose piece. The scaling factor utilized for this is as follows.

$$
f_{s c}=\frac{P}{w}=28.27
$$

where $f_{s c}$ is the scaling factor

$P$ stands for the perimeter of the mid-diameter of hose piece

$w$ stands for the width of standard test specimen

Experimental data and simulation results for hose piece and standard test specimen are all in good agreement with one another to a displacement of $10 \mathrm{~mm}$. Afterwards, the difference between experimental data for the standard test specimen and experimental data for hose piece along with simulation results rises gradually. This increase of difference in reaction forces may be attributed to the difference in mechanical behaviour regarding standard test specimen and hose piece which is presented in Chapter 8 in detail. 


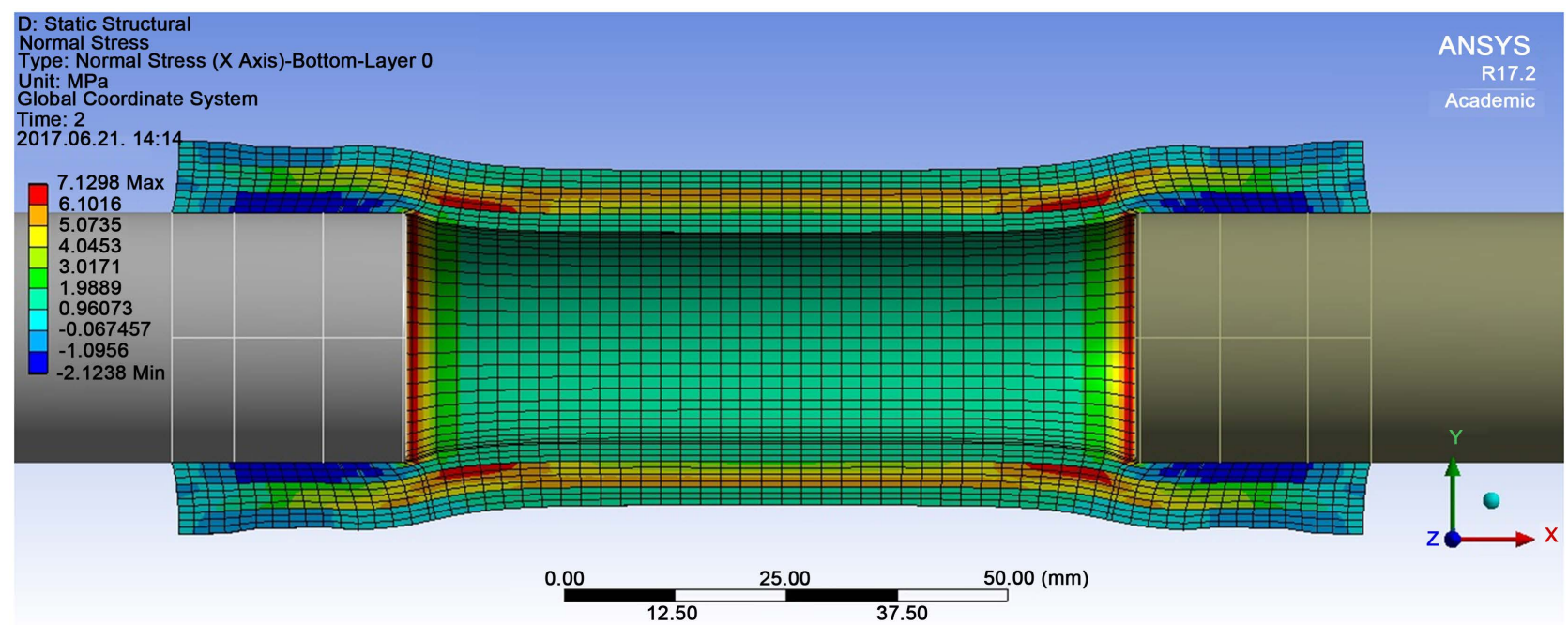

Figure 27. Longitudinal stress $\left(\sigma_{\mathrm{x}}\right)$ in the global coordinate system.

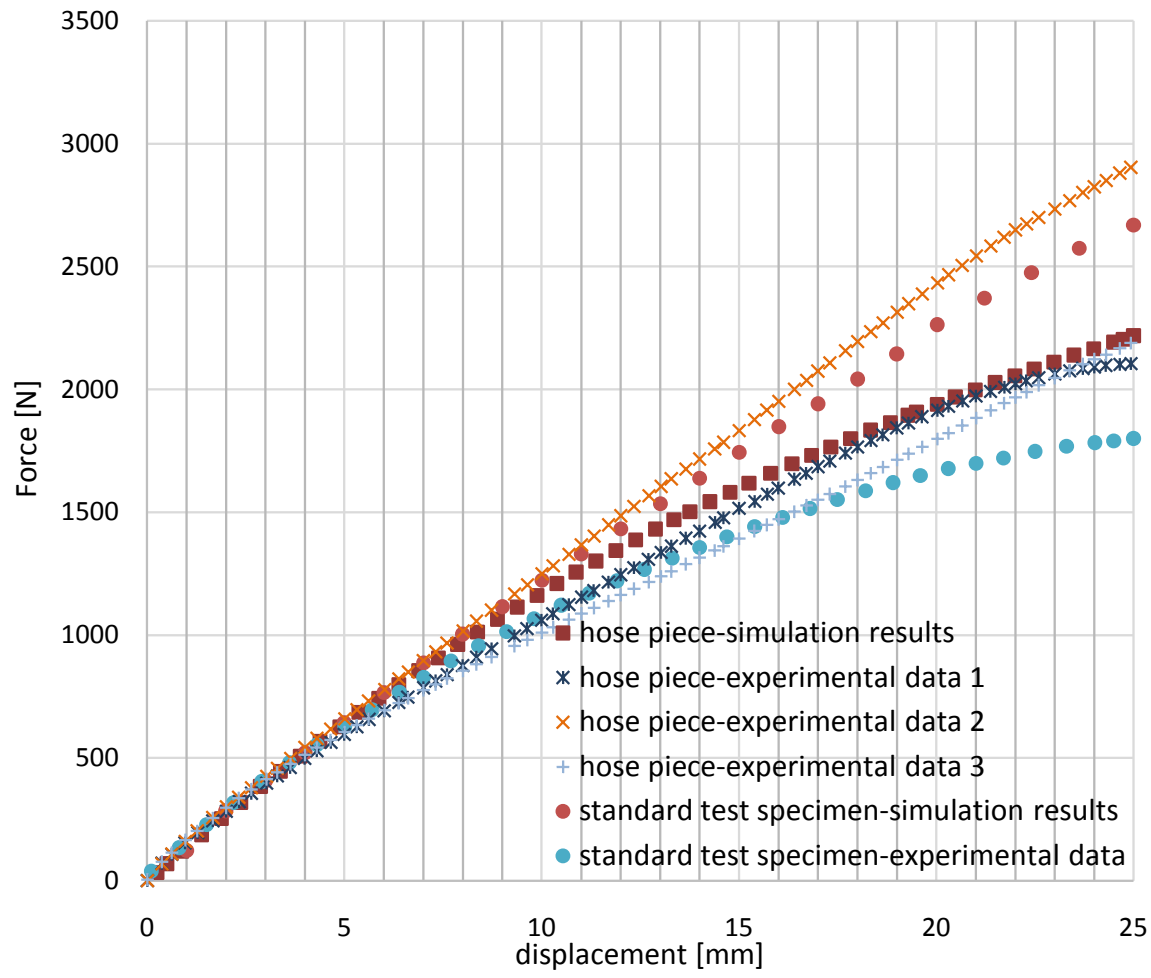

Figure 28. Force-displacement curves of hose piece and standard test specimen.

Table 4. Average stresses in reinforcement plies in the vertical midplane.

\begin{tabular}{ccccc}
\hline ply no. & $\sigma_{\mathrm{x}}[\mathrm{MPa}]$ & $\sigma_{1}[\mathrm{MPa}]$ & $\sigma_{2}[\mathrm{MPa}]$ & $\tau_{12}[\mathrm{MPa}]$ \\
\hline 1 & 6.63 & 5.44 & 2.94 & -2.66 \\
2 & 6.15 & 5.23 & 2.85 & 2.69 \\
3 & 4.31 & 0.37 & 2.83 & -2.7 \\
4 & 3.63 & 2.58 & 2.84 & 2.73 \\
\hline
\end{tabular}




\section{Conclusions}

Simulation results and experimental data of standard test specimen are in good agreement in the displacement interval of $0-10 \mathrm{~mm}$. Relatively high shear strain, $\gamma_{12}=0.26$ and significant normal strain $\mathcal{E}_{2}=0.11$ belongs to the end of this displacement interval.

Tension exerted on the standard test specimen causes shear and transverse tension in reinforcement plies because load is aligned off-axis to the yarns. Load is distributed among yarns by the rubber matrix, having low modulus of elasticity, being susceptive to shear. In the course of uniaxial tensile loading, yarns and matrix debond gradually within the plies (Figure 7). This procedure, taking place between displacements of 15 and $25 \mathrm{~mm}$ is nonlinear (Figure 19, Figure 28). Yarns in the standard test specimen are regarded as short yarns because the thickness of the specimen is small, which makes failure procedure initiate at low strain values.

However, in the case of the hose piece, reinforcement plies being intact and continuous, in which yarns are much longer than in standard test specimen, are less susceptible to intra-ply yarn-matrix debonding. Continuous plies make the hose piece stiffer in radial direction (Figure 20, Figure 24), which raises resistance against tension, thus generating higher forces at the same displacement values (Figure 28). Tension causes less transverse normal stress and shear stress in hose piece compared to the case of standard test specimen (Table 2 and Table 4 respectively).

With respect to the hose piece, the difference between simulation results and experimental data regarding force-displacement values is less than $10 \%$ of the experimental data (Figure 23). Finite element results of standard test specimen and finite element results of hose piece are in good agreement in the initial phase of uniaxial tension. Experimental results and FE simulation results, regarding standard test specimen and hose piece, also show good agreement in this section of uniaxial tension.

\section{Acknowledgements}

Authors would like to express their gratitude to Department of Polymer Engineering, Budapest University of Technology and Economics namely to Gábor Szebényi and Balázs Pinke for providing them with the testing environment, moreover to György Szabó at the Department of Machine and Product Design, Budapest University of Technology and Economics for test specimen preparation and to eCon Engineering Ltd., namely to Dániel Farkas for valuable recommendations regarding the scope of this study.

The recent study and publication was realized within the Knorr-Bremse Scholarship Program supported by the Knorr-Bremse Rail Systems Budapest.

\section{References}

[1] Braiek, S., Zitoune, R., Ben Khalifa, A. and Zidi, M. (2017) Experimental and Nu- 
merical Study of Adhesively Bonded $\pm 55^{\circ}$ Filament Wound Tubular Specimens under Uniaxial Tensile Loading. Composite Structures, 172, 297-310.

https://doi.org/10.1016/j.compstruct.2017.03.103

[2] Almeida Jr., J.H.S., Ribeiro, M., Volnei, T. and Amico, S.C. (2017) Damage Modeling for Carbon Fiber/Epoxy Filament Wound Composite Tubes under Radial Compression. Composite Structures, 160, 204-210. https://doi.org/10.1016/j.compstruct.2016.10.036

[3] Carroll, M., Ellyin, F., Kujawski, D. and Chiu, A.S. (1995) The Rate-Dependent Behaviour of $\pm 55^{\circ}$ Filament-Wound Glass-Fibre/Epoxy Tubes under Biaxial Loading. Composites Science and Technology, 55, 391-403. https://doi.org/10.1016/0266-3538(95)00119-0

[4] Hinton, M.J., Soden, P.D. and Kaddour, A.S. (1995) Strength of Composite Laminates under Biaxial Loads, Proceedings of 10th Int. Conf. on Composite Materials (ICCM-10), IV, Whistler, British Columbia, Canada, 65-72.

[5] Soden, P.D., Kitching, R., Tse, P.C. and Tsavalas, Y (1993) Influence of Winding angle on the Strength and Deformation of Filament-Wound Composite Tubes Subjected to Uniaxial and Biaxial Loads. Composites Science and Technology, 46, 363-378. https://doi.org/10.1016/0266-3538(93)90182-G

[6] Zhang, L. and Li, H. (2011) Investigation on Mechanical Behavior of Filament-Wound CFRP Tubes. Proceedings of SPIE, 7978, 79781Y-6.

https://doi.org/10.1117/12.880372

[7] Soden, P.D., Kitching, R. and Tse, P.C. (1989.) Experimental Failure Stresses for $\pm 55^{\circ}$ Filament Wound Glass Fibre Reinforced Plastic Tubes under Biaxial Loads. Composites, 20, 125-135. https://doi.org/10.1016/0010-4361(89)90640-X

[8] Hull, D., Legg, M.J. and Spencer, B (1978) Failure of Glass/Polyester Filament Wound Pipe. Composites, 9, 17-24. https://doi.org/10.1016/0010-4361(78)90513-X

[9] Wang, Z., Liu, W. and Du, Y. (2012) Experimental Study of the Mechanical Properties of the Composite Materials Hose. Advanced Materials Research, 496, 3-6. https://doi.org/10.4028/www.scientific.net/AMR.496.3

[10] Bai, J., Seeleuthner, P. and Bompard, P. (1997) Mechanical Behaviour of $\pm 55^{\circ} \mathrm{Fi}-$ lament-Wound Glass-Fibre/Epoxy-Resin Tubes: I. Microstructural Analyses, Mechanical Behaviour and Damage Mechanisms of Composite Tubes under Pure Tensile Loading, Pure Internal Pressure, and Combined Loading. Composites Science and Technology, 57, 141-153. https://doi.org/10.1016/S0266-3538(96)00124-8

[11] Manach, P.Y. (2008) Experimental Study of the Mechanical Properties of the Composite Materials Hose. Applied and Computational Mechanics, 2, 291-302.

[12] Kollár, L.P. and Springer, G.S. (2003) Mechanics of Composite Structures. Cambridge University Press, Cambridge. https://doi.org/10.1017/CBO9780511547140

[13] KLONK User's Manual. http://www.imagemeasurement.com/en/manual

[14] Ansys Mechanical User's Guide, Engineering Data User's Guide, Material Data, Mechanical Material Curve Fitting.

[15] Chawla, K.K. (2009) Composite Materials Science and Engineering. 3rd Edition, Springer, New York, London.

[16] Chamis, C.C. (1983) NASA Tech. Memo. 83320. 38th Annual Conference of the Society of Plastics Industry, Houston.

[17] Karger-Kocsis, J., Mousa, A., Major, Z. and Békési, N. (2008) Dry Friction and Sliding Wear of EPDM Rubbers against Steel as a Function of Carbon Black Content. Wear, 264, 359-367. 